\title{
Alternative way for using wastewater treatments in agro management techniques using micro irrigation systems: A review
}

\author{
${ }^{1}$ Abou Seeda M.A., ${ }^{2}$ Abou El-Nour E.A.A., ${ }^{3}$ Hammad S.A. and ${ }^{1}$ Yassen A.A. \\ ${ }^{1}$ Plant Nutrition Dept., National Research Centre, 33 El Buhouth St., 12622 Dokki, Giza, Egypt. \\ ${ }^{2}$ Fertilization Tech. Dept., National Research Centre, 33 El Buhouth St., 12622 Dokki, Giza, Egypt. \\ ${ }^{3}$ Soil and Water Dept., Faulty of Agric., Mansoura University, Egypt.
}

Received: 20 July 2020 / Accepted 30 Sept. 2020 / Publication date: 10 Oct. 2020

\section{BSTRACT}

In arid and semi-arid regions of the world, water has become a limiting factor, particularly for agricultural and industrial development. Water resources planners are continually looking for additional sources of water to supplement the limited resources available to their region. Several countries of the Eastern Mediterranean region, for Example, where precipitation is in the range of 100-200 $\mathrm{mm} \mathrm{a}^{-1}$. In such situations, source substitution appears to be the most suitable alternative to satisfy less restrictive uses, thus allowing high quality waters to be used for domestic supply. Consider low quality waters such as wastewater, drainage waters and brackish waters should, whenever possible, as alternative sources for less restrictive uses. Agricultural use of water resources is of great importance due to the high volumes that are necessary. Irrigated agriculture will play a dominant role in the sustainability of crop production in years to come. The use of appropriate technologies for the development of alternative sources of water is, probably, the single most adequate approach for solving the global problem of water shortage, together with improvements in the efficiency of water use and with adequate control to reduce water consumption. The use of wastewater constitutes an important element of a water resources policy and strategy. Many nations, particularly those in the arid and semi-arid regions such as the Middle Eastern countries, have adopted in principle the use of treated wastewater as an important concept in their overall water resources policy and planning. However, accompanied with an extensive implementation of sewage irrigation, some problems with sewage irrigation became gradually obvious in agriculture, especially those related with pollution and destruction of farmlands. In this paper, the effects of sewage irrigation on soil physical (soil bulk density, soil resistance to penetration and field capacity), chemical ( $\mathrm{pH}$, soil organic matter, nitrogen, phosphorus, potassium, heavy metal and organic pollutants) and biological characteristics (soil microorganisms and enzyme activities) were systematically reviewed. To ensure long-term sustainability, sufficient attention must be given to the social, institutional and organizational aspects of effluent use in agriculture and aquaculture. The reuse of WW finds increased application in irrigation but the presence of toxic elements and microorganisms limits its use for irrigation purpose. To reduce the contamination of WW for irrigation, drip system is seen as an appropriate choice due to restricted quantity of water application. Emitter clogging is viewed as the main problem associated with drip system for its large-scale use with WW. Physical and chemical characteristics of WW were restricted. Higher $\mathrm{EC}, \mathrm{pH}, \mathrm{Mg}$, and $\mathrm{CO}_{3}$, higher turbidity, total solids, $\mathrm{HCO}_{3}$, and $\mathrm{Ca}$ were observed in the waste water treatments.

Keywords: Alternative way, wastewater treatments, Microirrigation systems.

\section{Introduction}

\subsection{Water availability}

More than $97 \%$ of the water of the Earth planet is seawater, $2 \%$ is locked in icecaps and glaciers, and a large proper on of the remaining 1\% lies to underground to exploit it (Postel, 1992). Fortunately, a tiny fraction of the planet's water (less than $0.3 \%$ ) is renewed and made fresh by nature's solarpowered water cycle (Jackson et al., 2001).

One of the clearest signs of water scarcity is the increasing number of countries in which population has surpassed the level that can be sustained comfortably by the water available (Postel, 1992). Growing water scarcity, rapid increase in population, rapid urbanization and megacity development, increasing competition among water users, and growing concerns for health and

Corresponding Author: Abou Seeda M.A., Plant Nutrition Dept., National Research Centre, 33 El Buhouth St., 12622 Dokki, Giza, Egypt. E-mail:mabouseeda@gmail.com 
environment protection are important examples in water security and availability issues (Lazarova and Asano, 2005). Despite improvements in the efficiency by water use in many developed countries, the demand for fresh water has continued to climb as the world's population and economic activity have expanded (Lazarova and Asano, 2005). In 1995 about 2.3 billion people (41\% of the world's population at the time) resided in river basins considered to be water stressed $\left(<1700 \mathrm{~m}^{3}\right.$ of water person $\left.{ }^{-1} \mathrm{yr}^{-1}\right)$ and this value has been predicated to increase to 3.5 billion by 2025 ( $48 \%$ of the projected popula on). Of these, 2.4 billion will live under high water stress conditions (World Resources Institute, 2000). On the other hand, water for agriculture is critical for food security. Agriculture remains the largest water user, with about $70 \%$ of the world's freshwater consumption (Lazarova and Asano, 2005).

The challenged to satisfy the irrigation water demand under conditions of increasing water scarcity in both developed and emerging is to conserve water and improve the efficiency of water use through better water management and policy reforms (Lazarova and Asano, 2005). Therefore, many strategies will be needed to be implemented during the coming decades to deal with water stress, and wastewater irrigation will undoubtedly be one of the most important strategies. Wastewaters of municipal origin are used to irrigate a wide variety of crops and landscapes across the world (Hamilton et al., 2007).

\subsection{Irrigation with recycled effluent: benefits and constraints}

The most accepted goal for wastewater treatment and reuse projects is to produce water to sufficient quality to be used for all the potential uses that do not require drinking water quality standards, such as agricultural and landscape irrigation, industrial uses and non-potable urban uses Sala and Serra, (2004). Many potential advantages exist for irrigation crops with effluent instead of fresh water, regardless of the irrigation system type, such as:

- Conserve potable water resources by providing another alternative water resource for irrigation (Lazarova, 2005; Lazarova and Asano, 2005; Trooien and Hills, 2007; Kiziloglu et al., 2008).

- Reduce wastewater discharge to the environment, particularly to sensitive coastal, lacustrine and riverine systems (Anderson, 2003; Hamilton et al., 2006, Aronino et al., 2009).

- Decrease the use of fertilizers thanks to the nutrients present in the applied effluents (Haruvy, 1998; Meli et al., 2002; Ramirez-Fuentes et al., 2002; Trooien and Hills, 2007).

- Increase the productivity and yield of some crops e.g. celery، eggplant، lettuce، maize and sorghum) due to the effluent content of the fertilizers (Kaddous and stubbs, 1983; Chakrabar, 1995; AlNakshabandi et al.,1997; Marecos Do Monte,1998; Sheikh et al., 1998)

- The metabolism activity of soil microorganism increase when sewage effluents were used for irrigation (Marecos Do Monte, 1998)

- Cost/ benefit ratio favorable in some situations (Lazarova and Ansano, 2005).

- A possibility of decreasing the purification level and the derived treatment costs, thanks to the role of soil and crops in acting as a bio-filter (Haruvy, 1998).

However, as well as using treated wastewater for irrigation has great benefits, it is also may have some constraints in some cases, just as:

- The over concentration of nutrients in wastewater leads to reduce crop size and quality, delay matura of sun owner (Marecos Do Monte, 1998) and affect the plant ability to resist diseases (Wright, 1993).

- Environmental problems, such as water eutrophication may occur in consequence of using effluent for irrigation (Sala and Mujeriego, 2001).

- In case of high $\mathrm{C} / \mathrm{N}$ ratio, soil micro fauna would be increased which leads to pores-clogging problems in the soil matrix due to a signification decrease of the soil hydraulic conductivity (Magesan et al., 2000).

- Leaching nutrients and other solutes poses one of the greatest threats to groundwater health (Bond, 1998; Haruta et al., 2008).

- Possible contamination with heavy metals. However, in the treated wastewater effluents, the concentration of heavy metals is smaller (Sheikh et al., 1998; Hamilton et al., 2007).

- Irrigation with wastewater effluents could raise the sanitary problems, such as risk of viral and bacterial infections for both farmers and crops (Blumenthal et al., 2000; Pereira et al., 2002). Nevertheless, when effluent is treated following the allowed standards provided by the international organizations, e.g. WHO, health risks will be reduced. 


\subsection{Wastewater treatment and recycling}

Wastewater derived from municipal treatment facilities is becoming an important source of water of irrigation, being in some localities the only available source of water. Nevertheless, as irrigation with effluents raises health problems Pereira et al., (20002), some restrictions have been placed on its use especially, for the irrigation of edible crops (Trooien and Hills, 2007). In Spain, the Royal Decrease 1620/2007, BOE, (2007) establishes the legal framework for the reuse of treated water. Micro irrigation is particularly, suitable for wastewater reuse because it minimizes the health risks to farmers and product consumers (Orno et al., 1992). However, in micro irrigation system, the most important problems that face the irrigators with reclaimed effluents are emitter and filter clogging that lead to low system distribution uniformity. For the importance of clogging problems and system distribution uniformity in the micro irrigation systems regarding to the scope of the present study, will be discussed in details. Most engineers agree that the choice of water treatment process depends on water supply source, required finished water quality, capital and operating costs, process footprint versus ion availability, residuals disposal and applicability to multiple-barrier approach (Awwa, 2003). Nevertheless, the choice of wastewater treatment schemes depends on water quality requirement, type of irrigated crops (Lazarova, 2005). Before implementing any irrigation program with effluent, its characteristics must be analyzed.

There are many types of water treatment methods that are regularly used to improve water quality, remove microorganisms and reduce the level of toxic substances. These methods fall into the following general categories (Awwa, 2003):

- Air stripping and aeration. This method is used to remove dissolved gases, taste-and-odor compounds, and volatile organic compounds and to oxidize iron and manganese.

- Coagulation process that is used to aggregate small particles, such as clay, turbidity and organic matter into larger particles that can be removed using gravity processes.

- Ion exchange. This method is used to exchange unwanted ions for another ion.

- Chemical perception that uses chemical compounds to coagulate and flocculate the suspended material in the water.

- Membrane processes. These methods include microfiltration for removal of particles, ultra filtration for removal of large molecular weight organics, filtration for the removal of divalent ions, and the reverse osmosis for the demineralization process.

- Disinfection. This method is used to disinfect water and remove harmful microorganisms.

- Adsorption. This method uses powdered or granular activated carbon for the removal of dissolved organics, cooler and taste-and-odor causing compounds.

Usually wastewater treatment is classified into three types (Trooien and Hills, (2007). The first type is primary treatment that is generally a screening or settling process that removes organic solids from the effluent. The second type is the secondary treatment that is biological process that uses bacteria to remove complex material from the effluent. The third type is the tertiary treatment that includes membrane filtration and disinfection methods to produce water with a very high quality Photo. (1).

Activated sludge process is one of the biological treatment methods for wastewater. The conventional activated sludge exposes a variety of disadvantages, such as sludge expansion, little biomass and loose flocs structure. Therefore, the conventional activated sludge needs to be improved. Compared with conventional activated sludge, the magnetic separation technology could overcome the disadvantages and improve the performances of conventional activated sludge. In this paper, a magnetic activated sludge device was built to conduct a pilot-scale study for 124 days from municipal wastewater. The effects of conventional activated sludge and magnetic activated sludge on removing the organic matters and nitrogen were compared. In addition, the sedimentation performance of the magnetic activated sludge and the variations of the biomass concentration were also investigated. The measuring cylinder experiment showed that sludge velocity reduced from 90 to $56 \%$ after 2 min of settling $\left(\mathrm{SV}_{2}\right)$ with the variations of magnetic powder $\left(\mathrm{Fe}_{3} \mathrm{O}_{4}\right)$ dosage from 0 to $120 \mathrm{~g} / \mathrm{L}$. When the magnetic powder was added to aeration tank, the concentrations of mixed liquor volatile suspended solids (MLVSS) increased gradually and reached the maximum value of $7.35 \mathrm{~g} / \mathrm{L}$. The leakage of biomass was not observed during the magnetic activated sludge process, indicating that magnetic powder could maintain a high concentration of activated sludge. In addition, the magnetic powder had no negative influence on the growth of the activated sludge. Both processes did not have significant difference in removing chemical oxygen demand (COD) (above average: $75.13 \%$ removal) and biochemical oxygen demand 
for five days (above average: $92.79 \%$ removal). In contrary to the conventional activated sludge process, magnetic activated sludge process had higher removal efficiency in removing ammonium nitrogen $\left(\mathrm{NH}_{4}-\mathrm{N}\right)(88.68 \pm 7.98 \%$ removal). The average total nitrogen $(\mathrm{TN})$ removal efficiencies of both processes were $37.56 \pm 14.35 \%$ and $42.35 \pm 22.65 \%$, respectively. The lower COD/TN might affect denitrification efficiency. In general, effluents that passed by the primary treatment may be used for micro irrigation systems, but additional treatment may be required prior to effluent use. However, the second treatment is more adequate for agricultural micro irrigation system (Trooien and Hills, 2007). However, the type of treatment depends on the cultivated crop and the irrigation method according to the present regulation (BOE, 2007).

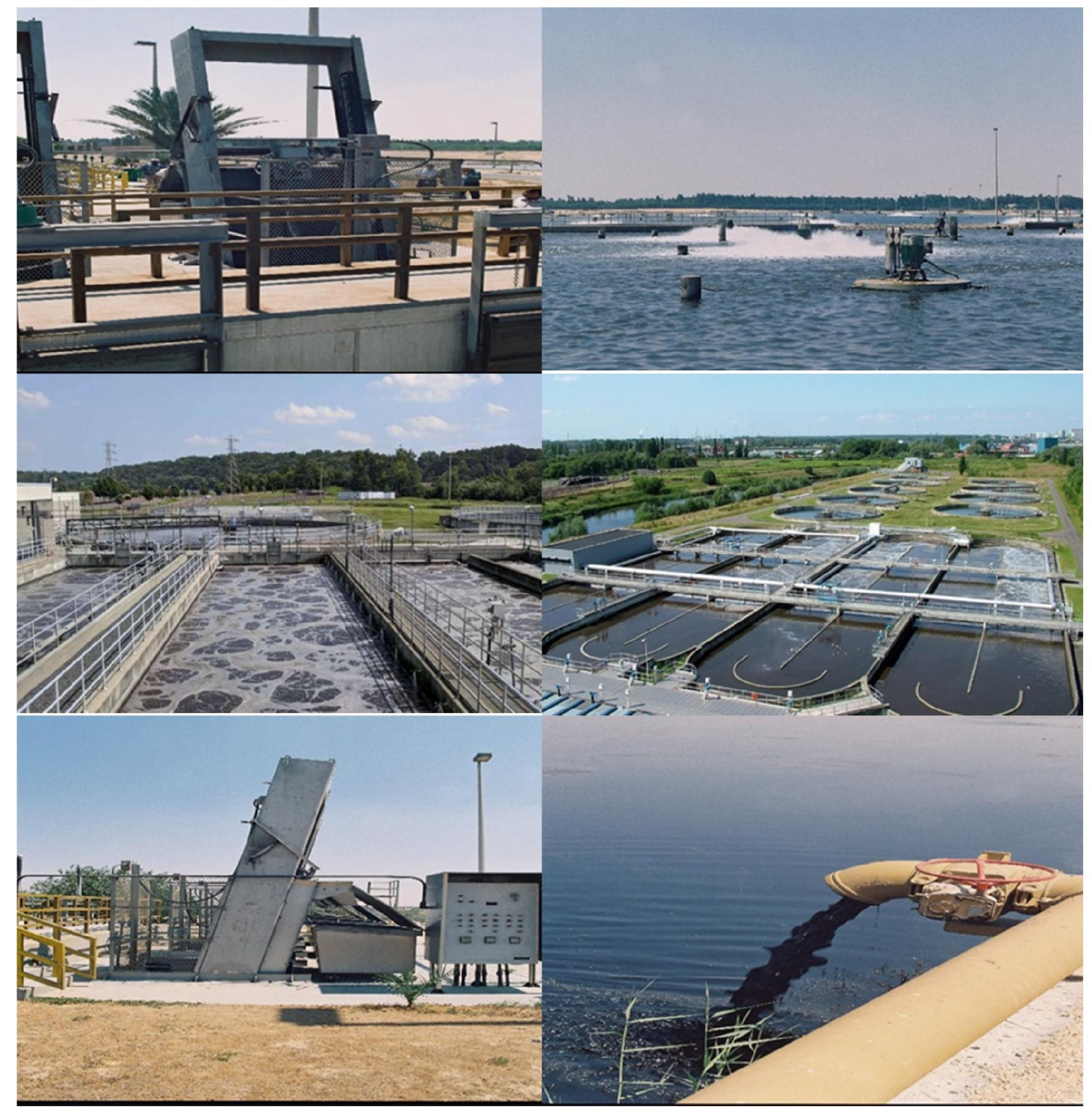

Photos 1: Illustrates some processing in wastewater treatments plants

\subsection{Micro irrigation systems}

Micro irrigation systems are usually defined in terms of installation method, emitter discharge rate, wetted soil surface area or mode of operation on (Ayars et al., 2007). According to ASAE (2001), Micro irrigation is the slow application of water on, above, or below the soil by surface drip, subsurface drip Photo (2), bubbler, and micro sprinkler systems. 

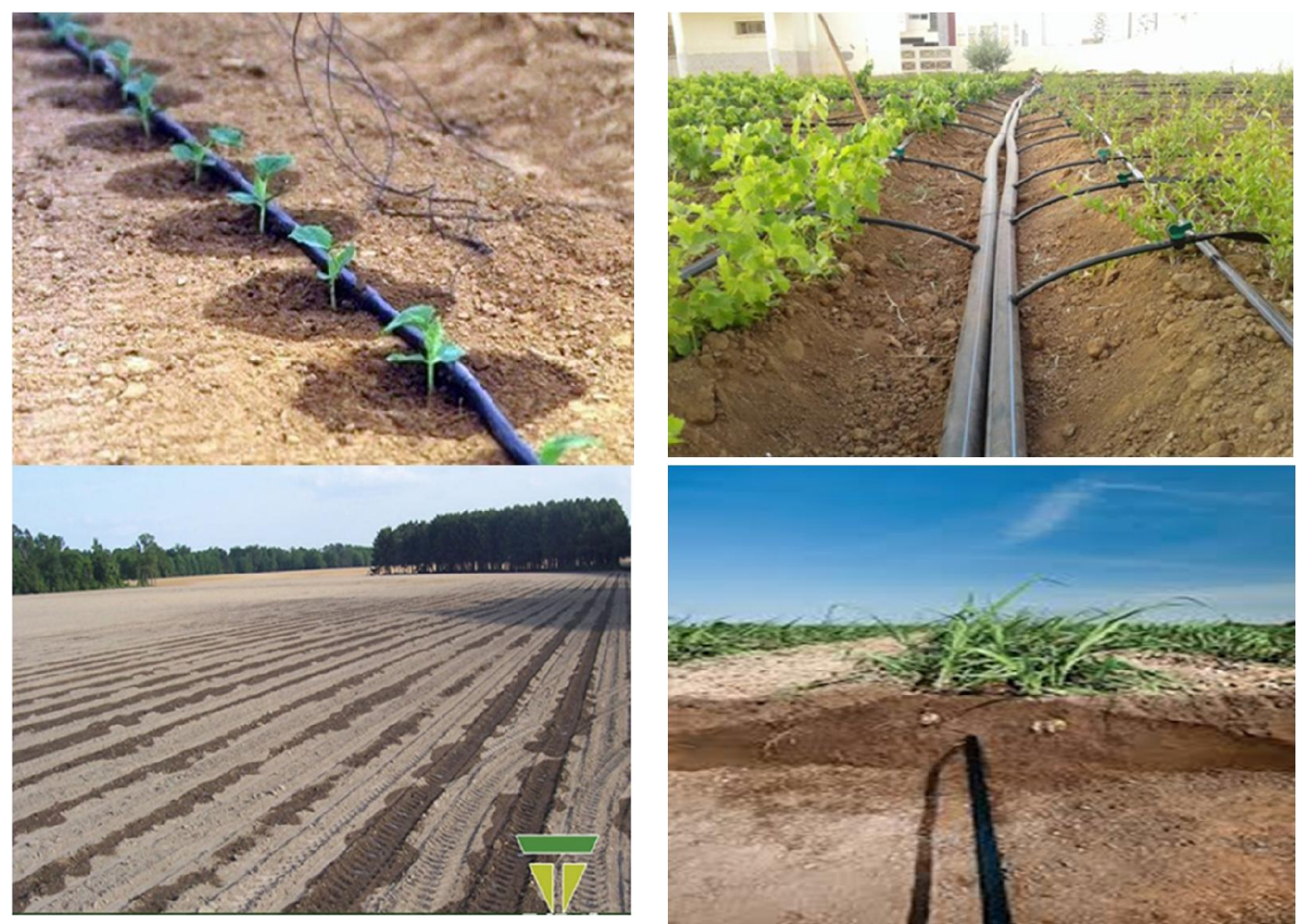

Photos 2: Represents drip and sub drip irrigation.

Water is applied as discrete or continuous drips tiny streams, or miniature spray through emitters or applicators placed among a water delivery line adjacent to the plant row during the last three decades, micro irrigation systems made major advances in technology development and uptake of the technology increased from 3 Mha in 2000 to more than 6 Mha in the world in 2006 (Reinders, 2000).

\subsubsection{Advantages and disadvantages of micro irrigation systems}

Micro irrigation, if properly managed, offers several potential advantages over other methods of irrigation (Pitts et al., 1990; Trooien et al., 2000; Ayars et al., 2007; Maestre-Valero and MartinezAlvarez, 2010).

- Greater water application uniformity and water use efficiency (improved crop yield and quality and reduced non-beneficial use and deep percolation).

- Improve cultural practice and weed control.

- Decrease energy requirement

- Safe use of biological effluent and treated wastewater as a valuable resource of water and in some cases nutrients and capability of using saline water.

- Reduced bacteria, fungi, disease and other pests that require a moist environment.

- Efficient delivery of fertilizer (fertigation) and other chemicals (chemigation) through the irrigation system.

- Ability to irrigate land too steep for irrigation by other means.

- Increase irrigation water dissolve oxygen concentration.

Finally, other additional advantages for applying effluents with

Subsurface drip irrigation (SDI) system include :Minimizes effluent odor and reduce human contact with it.

- Reduces significantly soil evaporation and salt concentration, which helps to diminish chemical clogging.

- Separation (setback) distance is decreased.

Drip line temperatures in subsurface drip irrigation (SDI) systems are lower, which may help to reduce biological and chemical clogging hazards. (Hills et al.,1989; Oron et al., 1992b; Gushiken 1995; Trooien et al., 2000; Lamm 2002; Orno et al., 2001): 
Despite the observed advantages of micro irrigation system, using effluents for micro irrigation system faces a serious problem that emitter clogging (Bucks et al., 1979; Adin and sacks 1987); Ravina et al., 1992). System (especially emitter) clogging or root intrusion in SDI system could cause nonuniformity or system failure (Ayars et al., 2007) Photo (3).

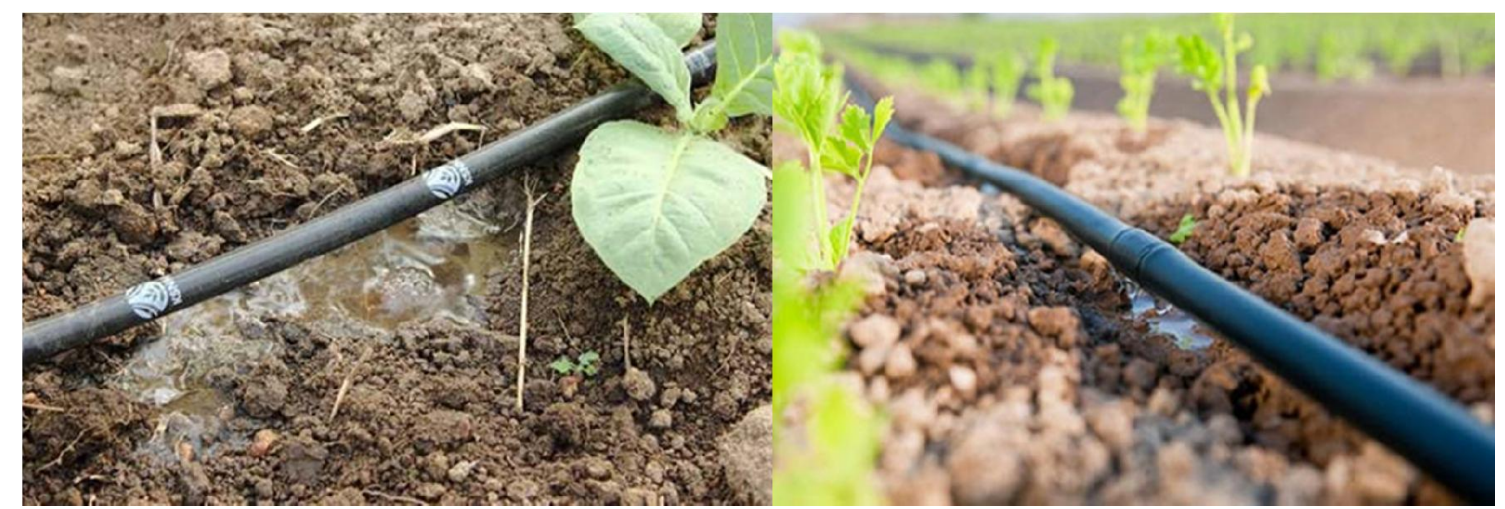

Photos 3: Illustrates some serious problems facing Microirrigation System (Especially emitter) clogging or root intrusion in SDI

Moreover, Ayars et al., (2007), also illustrated other problems and disadvantages such as

- Salt accumulation near plants Photo (4).

- Restricted root developed that has the potential to decrease plant growth and yields.
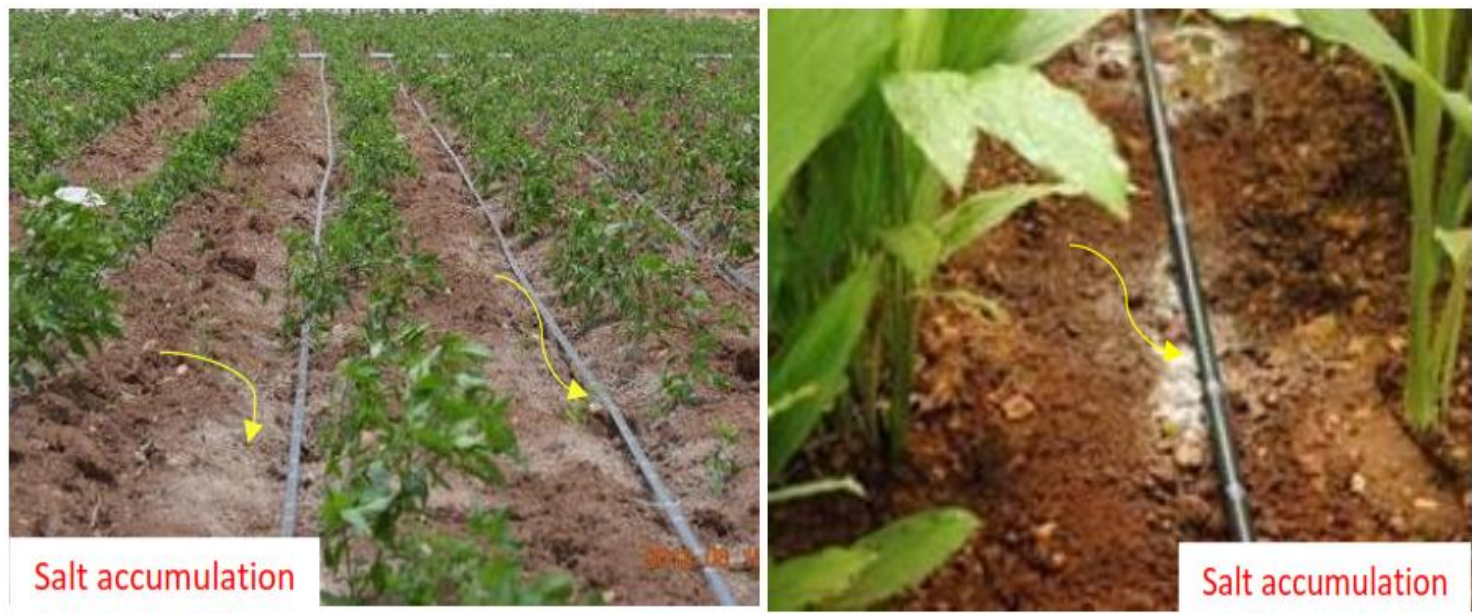

Photos 4: Accumulation of salts near plants that restricted root developing and decreasing plant growth and yields.

On the other hand, some potential disadvantages of applying biological effluent also exists Photos (5), regardless of micro irrigation system type, just as Trooien and Hills (2007):

- Land area requirements, maintenance requirements and installation costs could be increased.

- System performance monitoring requirements may be increased.

- Soil degradation could interfere with system operation or plant growth.

- Management may require more expertise. Limited experience could result in improper system design or management criteria.

Despite problems have occurred with wastewater that has been improperly treated Anderson (2003); Hamilton et al., (2006), those that have undergone adequate tertiary treatment generally have been successfully in micro irrigation (Nakayama et al., 2007). A greater understanding of the conditions that cause clogging may lead to improvement in operation and design for optimal treatment efficiency and improved system reliability (Leverenze et al., 2009). 
The main design for a micro irrigation system is to ensure that an acceptable uniformity of water application is obtained throughout the field by controlling emitter clogging to assure a suitable economic life for the micro irrigation system (Ayars et al., 2007). Micro irrigation system consists for a filtration unit for improving effluent characteristics and drip lines and emitters for maintaining a good distribution of the effluent in the field.
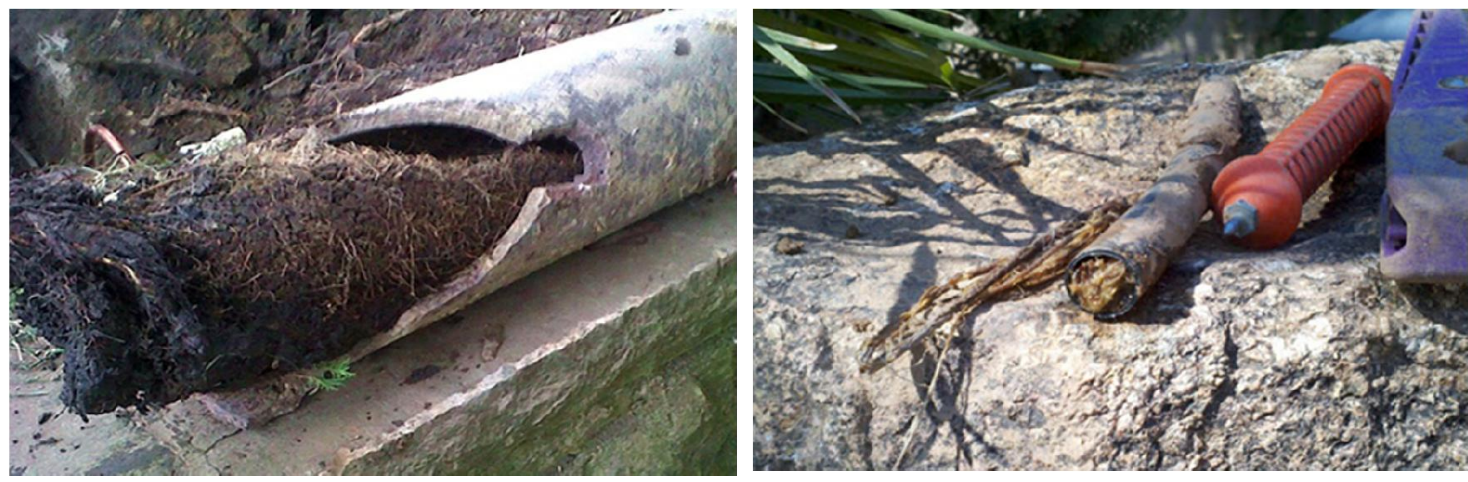

Photos 5: Illustrates some potential disadvantages of applying biological effluents Such as sewage water treatments

\section{Filtration and maintenance considerations for SDI systems}

All irrigation systems require proper maintenance and subsurface drip irrigation (SDI) systems are no exception. The major cause of failures in SDI and other micro irrigation systems worldwide is clogging. The emitters in SDI systems are small, leaving a small margin for error, so it is important to understand the filtration and maintenance requirements of SDI systems and take a proactive approach to the prevention of clogging. Fortunately, most SDI users in the Great Plains are pumping from highquality groundwater, such as the Ogallala aquifer, reducing the potential for clogging. Even so, proper steps must be taken to prevent clogging and maintain effective SDI system operation. With proper precautions and maintenance, SDI also can be used with surface water and other, lower quality, waters.

Prevention of clogging and proper maintenance of the SDI system start before it is installed. Chemical and biological analysis of the irrigation water will indicate which preventative filtration measures may be required to prevent clogging. Drip line requirements may also play a role in the selection of filtration measures to employ. Proper placement and use of flow meters and pressure gauges are required to provide feedback to the system operator. Monitoring the flow meters and pressure gauges over time can reveal system performance anomalies that may require attention. Check valves, air vents, and vacuum relief valves may be required at various places in the system to prevent entry of chemically treated water into the water source and soil particles into the drip lines. In addition, flush lines are required to occasionally remove the material accumulated in the drip lines (Hanson et al., 1994). Clogging hazards for SDI systems, regardless of the water source, fall into three general categories: physical, chemical, and biological. This paper will discuss prevention of clogging problems in these three categories with special emphasis on how they apply to SDI systems in the Great Plains (Alam, 1996).

\subsection{Description of DI and SDI irrigation systems}

Surface drip and subsurface drip irrigation systems have been used. In the surface drip irrigation system (DI), emitters and lateral lines were laid in the soil surface. On the other hand, in subsurface drip irrigation (SDI), water is applied slowly below the soil surface through buried emitters. A continuous monitoring and control of system performance was provided to achieve the maximum efficiency of the irrigation operation (Clark and Phene, 1992). The continuous monitoring helps to avoid any disruption schedule during the experiment. Moreover, the systematic inspection of micro irrigation system was required to spot the malfunctioning emitters, pipelines, leaks and accessory equipment failures (Abbott, 1985). 


\subsection{Filtration}

There is universal agreement that prevention rather than cleaning is the best method of reducing or overcoming emitter clogging. Cleaning refers to the flushing process of filters and laterals in the micro irrigation systems. Filtration is a key aspect in micro irrigation systems that use wastewater (Orno et al., 1979; McDonald et al., 1984). Effluent filtration prevents immediate clogging by large particles (Adin and Sacks 1991), but not completely (Tajarishy et al., 1994). Adequate water ltra on is primary requirement for reliable emitter operation. Filtration systems must be able to handle local peak loads in suspended particulates from the source water (Nakayama et al., 1978). In general, particles present in water range in size from the submicron virus to the large sand-size fractions as listed in Table (1)

Table 1:Represent screen filter opening sizes

\begin{tabular}{|c|c|c|c|}
\hline Particle diameter $\boldsymbol{\mu}$ & & \multicolumn{2}{|c|}{ Particle designation } \\
\hline$>1000$ & & \multicolumn{2}{|c|}{ Coarse sand } \\
\hline $250-500$ & & \multicolumn{2}{|c|}{ Medium sand } \\
\hline $50-250$ & & \multicolumn{2}{|c|}{ Very fine sand } \\
\hline $2-50$ & & \multicolumn{2}{|l|}{ Silt } \\
\hline$<2$ & & \multicolumn{2}{|l|}{ Clay } \\
\hline $0.4-2$ & & \multicolumn{2}{|c|}{ Bacteria } \\
\hline$<0.4$ & & \multicolumn{2}{|l|}{ Virus } \\
\hline Mesh & Inches & $\mathbf{m m}$ & Micron \\
\hline $\mathbf{0}$ & 0.017 & 0.425 & 425 \\
\hline 100 & 0.006 & 0.150 & 150 \\
\hline 150 & 0.004 & 0.105 & 105 \\
\hline 200 & 0.003 & 0.075 & 75 \\
\hline 270 & 0.002 & 0.053 & 53 \\
\hline 400 & 0.0015 & 0.038 & 38 \\
\hline
\end{tabular}

Physical clogging hazards are usually removed with screen filters. Sizing of screen filters is based on the maximum particle size allowable by the designed SDI system, quality of the irrigation water, the flow amount between required cleanings, and the allowable pressure drop across the filter. The maximum allowable particle size should be available from the drip line manufacturer. If not, a rule of thumb is to use 0.1 times the smallest diameter in the emitters used. A 200-mesh screen filter will remove the fine sand and anything larger, and is usually adequate for SDI systems in the Great Plains. Flow rates through screen filters should not exceed $200 \mathrm{gpm}$ per square foot of effective filter area. The effective filter area is defined as the area of the openings in the filter screen. Screen filters should be cleaned (back flushed) when the pressure drop across the filter increases by 3 to 5 psi or as recommended by the filtration system manufacturer. Automatic flushing is available on some filtration systems. Also available are self-cleaning screen filters called "spin filters." These are continuousflushing units. They swirl the water inward. Filtered particles move to the bottom of the filter and eventually leave the bottom of the filter through an open hole. A small amount of water is continuously pushing the filtered particles out the bottom and is therefore lost from the irrigation systems Fig. (1).

If large amounts of sand are in the water, a sand separator (also called a vortex sand separator or cyclone sand separator) may be required. Sand separators swirl the water and the centrifugal force separates the sand and other heavy particles from the water. If the amount of sand in the irrigation water is small, screen filtering will usually be adequate and a sand separator will not be required. For surface water, other steps may be required. For water with a large silt concentration, a settling basin may be required to remove the silt. Also for surface waters, pre-screening of the water to remove debris such as but not limited to stalks, leaves, and other plant residue may be required. When surface water is used for SDI, more extensive filtration systems such as media filters may be desirable Table (1). 


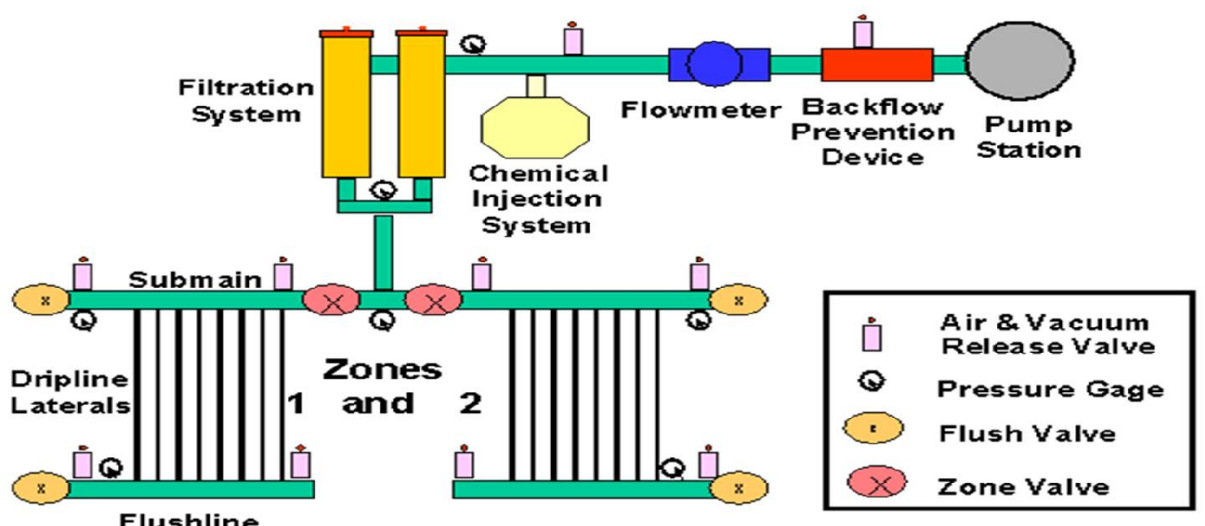

Fig. 1: Schematic of a subsurface drip irrigation (SDI) system.

In practice, the suspended solids concentration in surface irrigation water is much greater than $10 \mathrm{~g} \mathrm{~m}^{-3}$, which is a tremendous amount of solid that passes through drip lines and especially emitters. When the suspended materials are left in the drip lines, they can eventually become cemented together by microbial by products and chemical reactions to form larger particles. Consequently, significant changes can occur in the flow and pressure characteristics of the supply lines and emitters (Nakayama et al., 2007). Thus, a good filtration system to remove suspended material is an essential component of a micro irrigation system (Abbott, 1985). Nevertheless, the complete removal of suspended materials from water used for micro irrigation is impractical, being the removal of finer particles cost prohibitive. Therefore, water treatment aim primarily at removing the larger particle size and allowing the final suspended load to be in the range that emitters and delivery system can tolerate for long operational period (Nakayama et al., 2007).

Purchas and Sutherland (2002), filter medium as any material that, under operation conditions of the filter, is permeable to one or more components of a mixture, solution or suspension, and is impermeable to the remaining components. The principle role of the medium is to separate particulates from the liquid with the minimum consumption of energy.

To achieve this selection of correct medium takes into account factors such as the permeability of the clean medium, it's particle retention capability and the permeability loss of the medium during use (Wakeman, 2007). Filters must be matched to handle the flow rate of the irrigation system to the insure proper filtration (Neufeld et al., 1997). There are three common types of filters that used in micro irrigation system: Screen, Disc and Sand media filters (Abbott, 1985).

\subsection{Screen filters}

Screen filters are the most widely used filters in micro irrigation system.
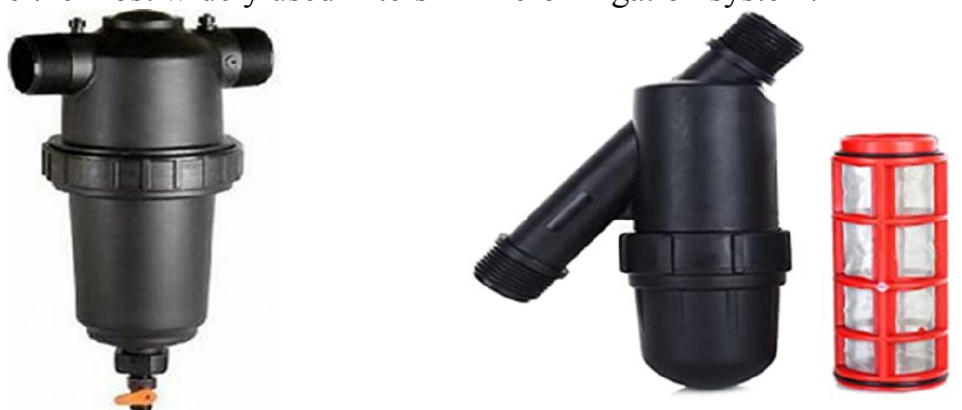

Fig. 2: Screen filter is produced from the non-toxic materials and is resistant and protected against degradation and type of water used in agricultural irrigation.

The screens that may be made of steel, plastic or synthetic cloth are enclosed in a pressurized housing and are popular because of their operation (Abbott, 1985). The method of operation varies with the manufacture's design and related to the way that water entry, circulation, and exit are handled. When 
properly sized and maintained, screen filters do an adequate job for removing suspended particles from the water. Self-cleaning screens provide a rotating mechanism inside the filter that can "scrub" contaminants off the surface of the screen when it starts to accumulate debris (Nakayama et al., 2007).

\subsection{Disc filters}

Disc filters use a series of grooved disc to form a filtering device when clamped together (Abbott, 1985).The ultraion on element in disc filters consists of several plastic or plastic-coated metal discs that are placed side-by-side on a telescopic circular shaft inside the housing Fig. (3). When these discs are stacked tightly together, they form a cylindrical filtering body, which resembles a deep tubular screen (Nakayama et al., 2007).
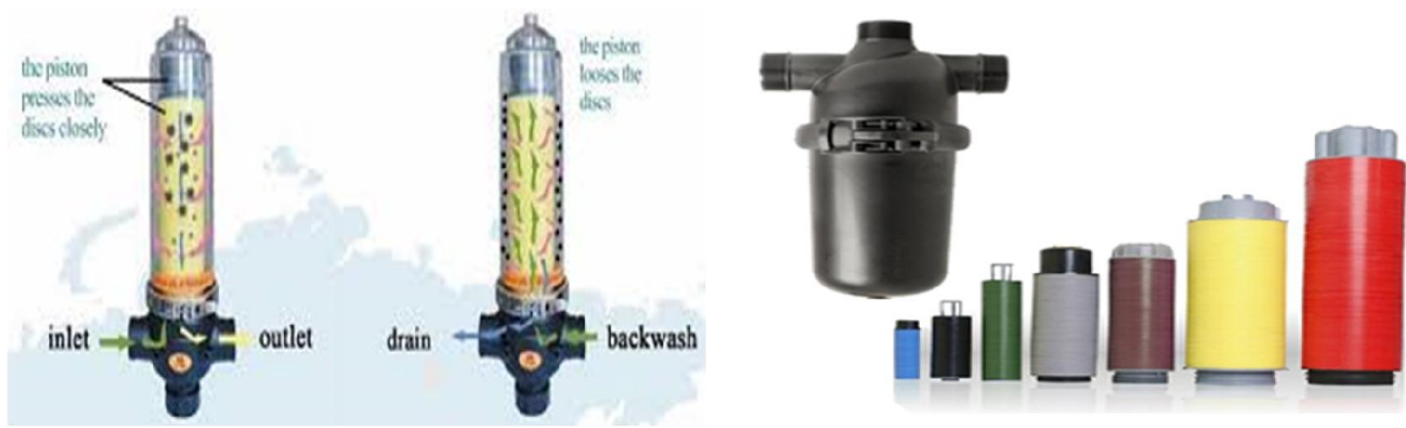

Fig. 3: Disc filter can use to filter different fluids especially

These filters have more surface area than screen filters of similar sizes and like screen, filters must be cleaned periodically (Burt et al., 1998).

\subsection{Media filters}

Media filters are usually consisting on sand and/or gravel of selected sizes placed in a pressurized tank (Abbott, 1985).Fig. (4).
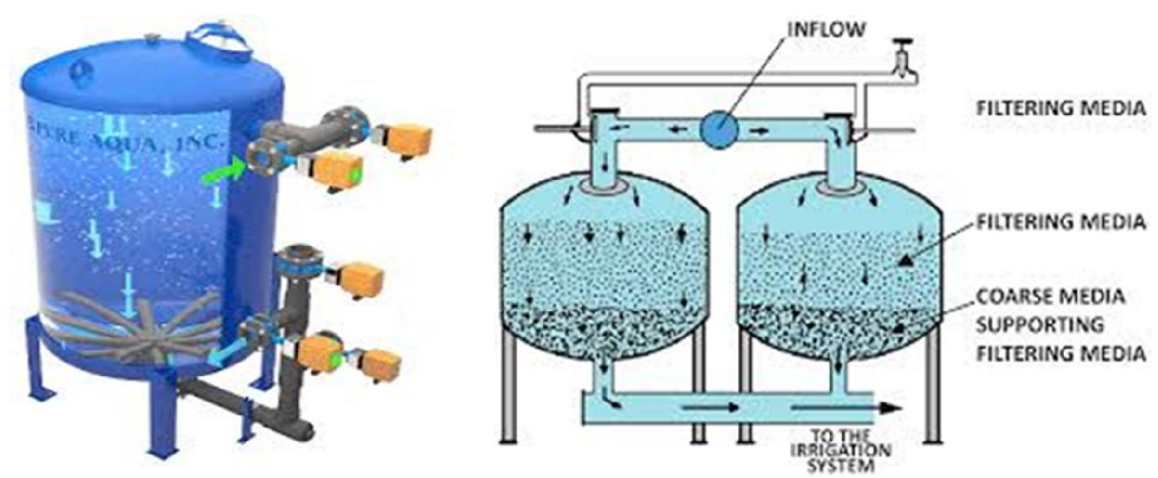

Fig. 4: Media filters which consists of sand or gravel of selected sizes placed in a pressurized tank

Nevertheless, many materials in diverse forms are used as a filter media. These include solid fabrications (e.g. wire wound tubes), metal sheets (e.g. fibrillated film) and membranes (Wakeman, 2007). Sand filters could remove particles down to around $10 \mu \mathrm{m}$. However, when used in conjunction with good flocculation, it is possible to consistently remove solids down to micron and sub-micron levels. This performance can only be maintained if there is zero channeling of water through the filter bed (Dryden, 2007). Pressure-type, high-flow sand or mix-bed media filters are the more popular one used to clarify irrigation water for micro irrigation systems. Almost the full depth of the sand is used in the pressurized filters compared with gravity filters, where surface action is the primary filtration mechanisms. These filters are cleaned by reversing flow water throughout the media to cause the separation and suspension of sand material into individual particles (Nakayama et al., 2007). On the other hand, sand filters have additional advantages like the removing viruses in the size range of 200 
$\mathrm{nm}$ (Aronino et al., 2009). They are as well suited for removal of inorganic particles beside the organic contaminants due to their three-dimensional nature that increases the ability to entrap large amounts of pollutants (Adin and Elimelech 1989; Adin and Sacks 1991; Haman et al., 1994; Phillips 1995; Ravina et al., 1997; Sawa and Frenken 2002). Therefore, sand media filtrate is often considered the standard for filtration protection of micro irrigation systems (Trooien and Hills 2007; Lamm et al., 1997 and Nakayama, and Bucks 1986).

\subsection{Choosing among filter types}

The choice between filters types depends on the origin and quantity of contamination anticipated in the system as well as the size of the irrigation system (Haman et al., 1994). Surface water requires a greater degree of filtration than groundwater. Relatively clean water may get by with a screen or disc filter, while dirtier water may require media filter (Neufeld et al., 1997).

Screen filters are a primary choice when water is pumped from a well where the only filtration requirement is to remove mineral particulate matter while media (sand) filters are recommended when large amount of algae Naghavi and Malone (1986) or other organic contaminants are present Haman et al., (1994) because screen filters cannot remove them without reducing the flow thus requiring frequent flushing (Chauhan, 1995). Other studies found also that disc and screen filters resulted in lower levels of turbidity and total suspended solids (TSS) than sand filters (Adin and Alon, 1986). In general, disc filters are a good choice for small flow rates because they have larger filtration capacity than screen filters, and because media filters are more expensive for low flow rates (Nakayama et al.,v2007) and have a bigger dirt-holding capacity than screen ones (Burt and Styles, 2000). This besides that, media filters are not typically available for small owns Burt and Styles, 2000). Even though, disc filters, on condition that are of good quality, are cheaper and similar to manage, and assured performance levels similar to those of the gravel media filters (Capra and Scicolone, 2004).

\subsection{Filter backwashing}

Filter's serious loss of permeability may follow plugging or blinding of the filter medium and can determine its life time if an uneconomic filtration rate results. Permeability and particle retention are dependent on interactions between the medium structure and the shape and size distribution of the particles in the feed suspension (Wakeman, 2007). Suspended materials trapped by the filter eventually decrease filtration efficiency and the filter must be cleaned. Cake formation or cementation on top of filter's surface during the initial stages of filtration causes a significant pressure drop that eventually results in shorter filtration cycles Aronino et al., (2009) and can result in complete clogging of the bed, or alternately, the formation of large continuous pores called "rat holes" that decrease filter performance (Nakayama et al., 2007).

Most manufactures of micro irrigation systems recommend high filtration levels. Consequently, in many cases of low quality waters, the main problems in the operation of drip irrigation systems have been clogged filters rather than emitters clogging (Ravina et al., 1997). Therefore, filters should be backwashed frequently (Pitts et al., 1990). The backwashing process consists on cleaning the filters by reversing the direction of water flow through the filtration media lifting it up to allow the dirty water to flow outside the filter (Abbott, 1985).Fig. (5a and b), illustrates the backwashing process in disc filter. Backwashing can be manual or automatic, on set time interval or at specific pressure drop. Either manual or automatic backwashing operations are available for media, screen or disc filters to improve filter function and efficiency. Excessive pressure loss across the filter is typically used to control automatic backwashing (Ayars and Phene, 2007). Burt and Styles (2000) recommended clean the filter when head loss across it reaches $35-55 \mathrm{KPa}$ for sand filters and $41.4-48.3 \mathrm{KPa}$ of disc ones. 


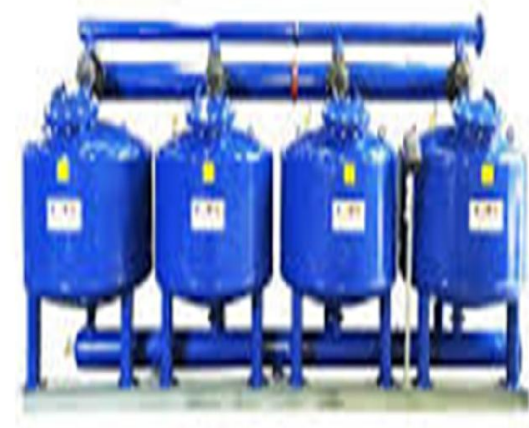

A

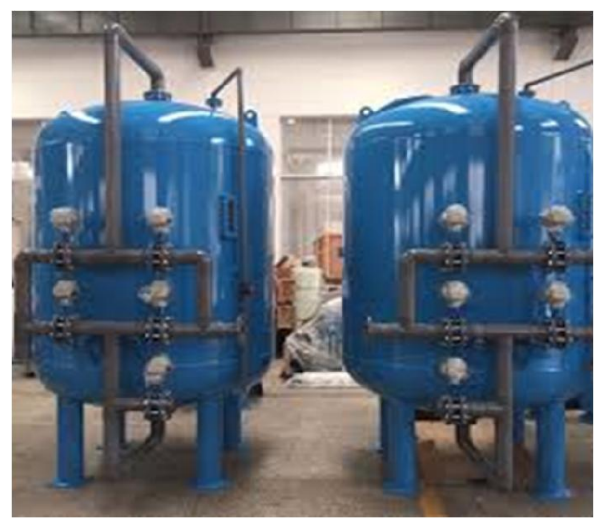

B

Fig. 5a: Manual / PLC Multimedia filter backwash, high pressure automatic screen filter

Fig. 5b: Automatic backwash water filters backwash sand filter $10 \mathrm{~mm}$ thickness

Ravina et al. (1992) recommended as well initiating the backwashing process when head loss across the filter reaches $50 \mathrm{KPa}$. Haman et al. (1994) recommended a range of 20-50 KPa for clean media filters depending on the size of the media and flow rate used. Yet, this is in the range set by Sawa and Frenken (2002) of $70 \mathrm{KPa}$ for sand filters.

The benefit of the automatic filter backwashing system is that it eliminates sudden change in water quality that can create problems if a filter is washed only at regular intervals Haman et al., (1994) and avoids the contact between the effluent and the irrigator (Capra and Scicolone, 2004).

Media filters are not easily blocked by algae or bacterial slimes and can removed large amounts of suspended solids before backwashing is required. Yet, they can provide conditions favorable for increased bacterial growth (Abbott, 1985).Nevertheless, filtration systems that have only one filter are impossible to be properly backwashed, as there will be no clean water from one filter to backwash the other (Sawa and Frenken, 2002).

The period of degraded effluent water quality passing through a filter immediately after being backwashed is called filter ripening. Even the ripening period has been deeply studied, scientists were forced primarily on effluent turbidity as a principal indicator to filter ripening determination (Pi sburgh Filtration commission, 1899; Amirtharajah and Wetstein, (1980); Amirtharajah, (1988); USEPA, (1998); Amburgey and Amirtharajah, (2005); and on particle size distribution Darby and Lawler, (1989), (1990). Amirtharajah (1988) showed that more than $90 \%$ of particles passing through a welloperated filter did so during the ripening period. Different estimations for filter ripening were pointed out. The USEPA (1998) pointed out that filtered effluent turbidity return to its normal value within 15 min of restart the backwashing. However, Amirtharajah (1988) indicated that effluent turbidity deterioration would occur anywhere from a few minutes to 40 or more after returning to filter operation mode.

\subsection{Emitters}

The key component of a micro irrigation system is the lateral that is placed in the crop root zone and delivers water to the crop. Water is conveyed through the lateral and into the soil profile through emitters, which are located within the lateral (Neufeld et al., 1997). Micro irrigation emitters are the small water-dispensing devices that are designed to dissipate pressure and constantly discharge a small and uniform flow of water (Clark et al., 2007)

Fig. (6).

Ideally, an emitter permits a small uniform flow of water at a constant discharge rate that does not vary significantly throughout the field or subunit (Ayars et al., 2007). Emitters have a several designs such as short-path, long-path, vortex, pressure compensating, self-flushing, perforated singleand double chamber tubing, as well as the aerosol emitters, foggers, misters, or the miniature sprays and sprinkles used in micro sprinkler irrigation. Many different emitters have been devised with the concept that the emitters should be inexpensive, reliable (not clog), and compact as well as provide a uniform water discharge (Ayars et al., 2007). 
In general, emitter discharge depends on the flow exponent value determined by the manufactures as shown in following equation.

$\mathbf{Q}=\mathbf{a} \cdot \mathbf{P}^{\mathbf{x}}$

Were $(\mathbf{Q})$ is emitter discharge $, 1 \mathrm{~h}^{-1},(\mathbf{a})$ is constant value, $(\mathbf{P})$ is working pressure head at the emitter, $\mathrm{KPa}$ and (x) is flow exponent .
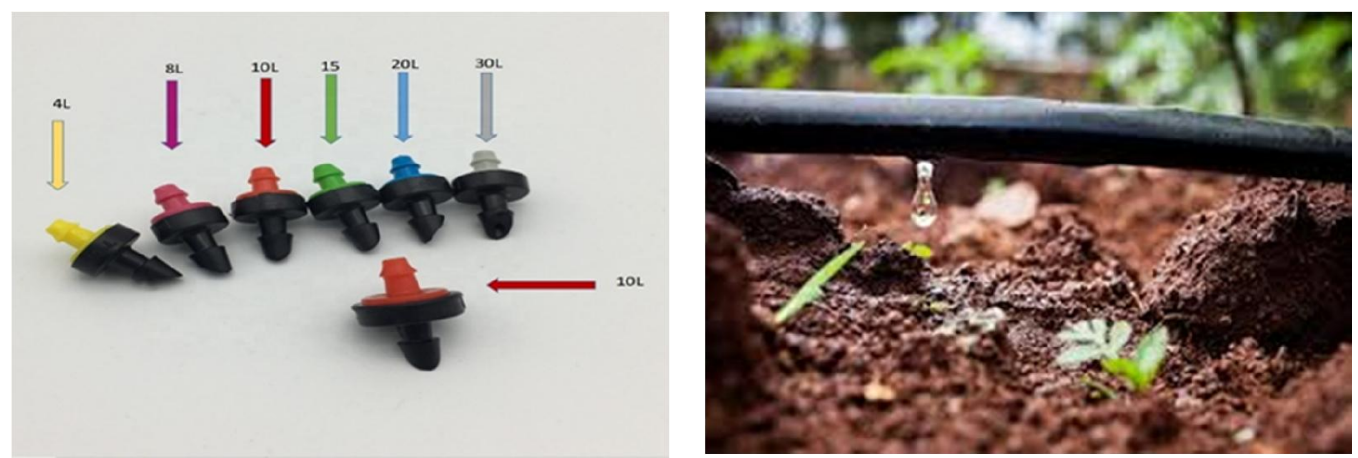

Photo 6: Some micro irrigation emitters, which are designed to dissipate pressure and constantly discharge a small and uniform flow of water

The sensitivity of an emitter discharge to the pressure head depends mainly on the value of $\mathrm{x}$. Laminar flow would give a straight line corresponds to $\mathrm{x}=1$; while a totally pressure compensating emitter would have a value of $x=0$, which corresponds to another horizontal line between these two extreme values ( 0 and 1$)$, exists a range of intermediate values, where the smaller the value of $x$ the smaller the impact of inlet water pressure variation-induced changes in discharge rate and uniformity (Medina, 1988). When $\mathrm{x}$ is equal to 0.5 , then ori ce or turbulent flow is occurring. This is similar to the discharge from many standard sprinkles. As the value of $\mathrm{x}$ decrease below 0.5 , pressure-compensating flow starts to occur (Clark et al., 2007). An example for emitter discharge relationship with emitter pressure head for three different emitter types is illustrated in Fig (2).

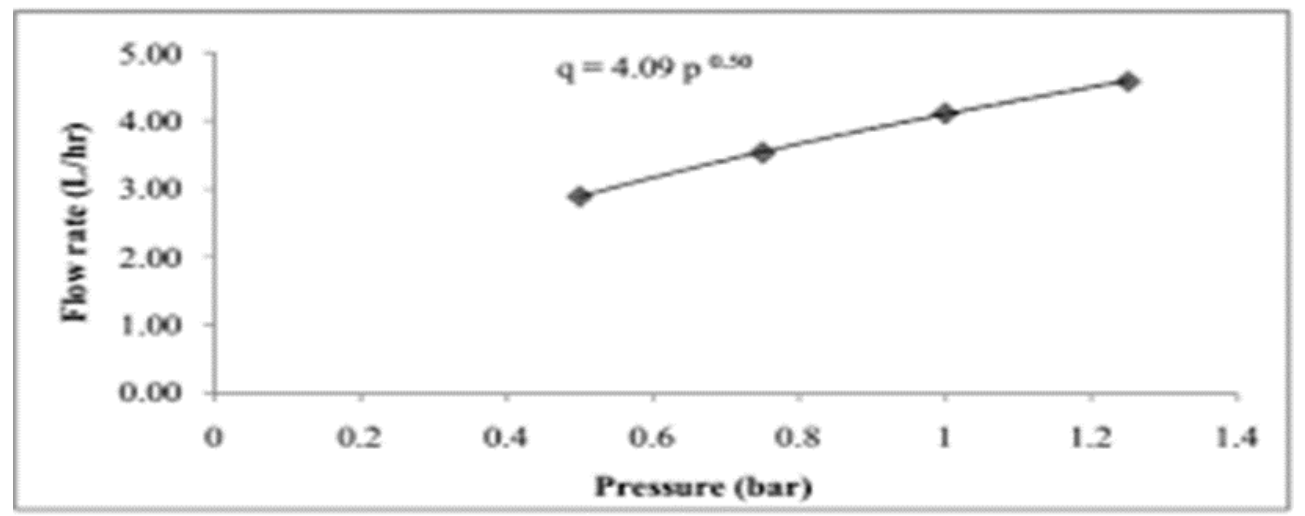

Fig. 2: Flow rate with pressure for built in GR emitters (4 L.hr-1) curve

The pressure compensating emitters are generally more expensive than the non-pressure compensating ones, and their performance affected by material fatigue caused by temperature, extended chlorination, microbial activity and acid injection in flushing process Ravina et al., (1992). Therefore, only under proper Microirrigation system design and with sufficient financial support, the pressure compensating emitters types are firstly recommended for drip irrigation with treated sewage effluents (Liu and Huang, 2009). Even though, the short path drippers are subject to the clogging by big particles that often occur at the beginning of water path and long path drippers are subject to the siltation by very tiny particles which deposit on the walls of the water path if the flow is not turbulent enough (Abbott, 1985). 


\subsection{Clogging problems}

One of the most serious problems that face the use of Microirrigation systems is emitter-clogging problem. Emitter clogging can be derived from physical, biological or chemical causes (Bucks et al., 1979).

\subsubsection{Physical Clogging}

Physical clogging is caused when different particles of sand and suspended debris that are too large to pass through the opening of emitters precipitate around it (Pitts et al., 1990; Adin and Sacks, 1991). Furthermore, sometimes the physical clogging problem may occur when clay particles flocculate and form aggregates even the unflocculated clay and silt-sized particles are normally too small to plug emitters (Pitts et al., 1990). Physical clogging of emitters takes two forms:

- Clogging by big particles often at the beginning of the water path. The change of emitter discharge in this situation is instantaneous

- Siltation by very tiny particles deposited on the wall of the water paths if the flow is not turbulent enough. The change of emitter discharge in this case very slow.

\subsubsection{Biological clogging}

Most micro irrigation systems suffer from emitter clogging due to biological activity and associated by-products. The organic material produced appears as slimy deposits in laterals and drippers and if allowed to build up, adversely affects the performance of the system. Suspended particles in the water also tend to stock to the biofilm and agglomerate (Abbott, 1985). The micro irrigation system can be provide a favorably environment for bacterial growth, resulting in biofilm buildup (Pitts et al., 1990) forming sediment in the emitter flow path (Dazhuang et al., 2009; Yan et al., 2010). This biofilm can combine with mineral particles in the water and form aggregates large enough to plug emitters ( $\mathrm{Li}$ et al., 2010; Yan et al., 2010; Li et al., 2011). Furthermore, certain bacteria can cause enough precipitation of manganese, sulphur and iron compounds to cause emitter clogging. In addition, algae can be transported into the irrigation system from the water source and create conditions that may promote the forma on of aggregates (Pitts et al., 1990).

Chlorine injection is usually used to assure that any unfiltered biological material does not accumulate elsewhere in the SDI system. If the microbiological load of the irrigation water is high, a low concentration ( 1 to $2 \mathrm{ppm}$ ) of chlorine should be injected continuously. If the biological load is not particularly high, a single clogging problem is severe, or biological clogging problems are due to sources other than irrigation water, chlorine shock treatment may be desirable. A shock treatment uses concentration of 10 to $30 \mathrm{ppm}$. Frequency and duration of shock treatments are determined by the severity of the problem. Chlorine gas is the most effective and least expensive chlorine source for injection but is hazardous and must be used with caution. Sodium hypochlorite (liquid bleach) is safer and easy to obtain and use. It degrades over time so it should not be stored for long periods before using. Calcium hypochlorite granules or tablets are more stable than bleach but more expensive.

\subsubsection{Chemical clogging}

Chemical clogging is usually the result of the precipitation of one or more of the following minerals Abbott (1985).Pitts et al., (1990): Calcium, magnesium, iron or manganese. The minerals precipitate from solution and form encrustations that may partially or completely block the flow of water through the emitter.

There are three different forms of chemical clogging Abbott (1985). - Clogging by evaporation at the end of the emitter path

- Clogging inside the dripper water path. This is frequently observed when fertilizers are used without sufficient care.

- Clogging of emitters at the beginning of the water path by scales of carbonates that break off deposits, which have formed on the walls of the plastic tubing.

\subsubsection{Other causes of clogging}

Moreover, other minor factors that cause emitter clogging such as ants, insect eggs and webbing have been reported (Abbott, 1985). These factors may be considered as physical clogging if the eggs are died or they may be considered as biological factors (Pitts et al., 1990). These factors are closely 
interrelated, and controlling one factor may alleviate problems caused by the others (Nakayama et al., 2007). For example, by reducing biofilm, the tendency of suspended solids particles to stick, agglomerate, and build up in micro irrigation drip lines and emitters are also reduced. In addition, small aquatic organisms such as snail eggs and larva, which are not readily observed and analyzed, can develop into large colonies in the lateral tubings and results in a combined physical and biological problem (Nakayama et al., 2007).

A summary for the principal physical, chemical and biological clogging factors in micro irrigation system is provided in Table (2)

Table 2: Some physical chemical and biological contributors to clogging Bucks et al. (1979).

\begin{tabular}{lll}
\hline $\begin{array}{l}\text { Physical } \\
\text { (suspended solids) }\end{array}$ & $\begin{array}{l}\text { Chemicals } \\
\text { (precipitation) }\end{array}$ & $\begin{array}{l}\text { Biological } \\
\text { (bacteria and algae) }\end{array}$ \\
\hline $\begin{array}{l}\text { Inorganic particles } \\
\text { Sand }\end{array}$ & $\begin{array}{l}\text { Calcium or magnesium carbonate } \\
\text { Calcium sulphate }\end{array}$ & Filaments \\
Silt & Heavy metal hydroxides, carbonates, & Slimes \\
Clay & Microbial depositions \\
Plastic & silicates and sulfides & Sulfur \\
$\begin{array}{l}\text { Organic particles } \\
\text { Aquatic } \\
\text { (phytoplankton/algae) }\end{array}$ & Fertilizers & Iron \\
$\begin{array}{l}\text { Aquatic animals (zooplankton) } \\
\text { Bacteria }\end{array}$ & Phosphate & Manganese \\
\hline
\end{tabular}

In general, the clogging problem increase when micro irrigation systems utilize treated effluent stored in surface reservoirs (Ravina et al., 1997). Surface water resources from rivers and unlined storages often give problems with suspended solids particularly, silts and clays while the water that comes from wells and bores often contains sand particles. Furthermore, chemical clogging problems are frequently reported from systems that use groundwater that often contains significant quantities of dissolved salts (Abbott, 1985).

Bucks et al. (1979) classified the effect of water resource according to its main physical, chemical and biological characteristics to slight, moderate and severe clogging hazard. These classification criteria of clogging potential of micro irrigation water sources are shown in Table (2), Bucks et al. classification is commonly used worldwide. Capra and Scicolone (1998) proposed a new clogging hazard no long, increasing the threshold values for suspended solids, electrical conductivity, iron and manganese removing parameters like $\mathrm{pH}$, hydraulic sulfide and bacterial population and introducing new parameters like calcium and magnesium. Liu and Huang (2009) pointed out that Bucks et al. (1979) criteria are better than those of Capra and Scicolone (1998) for assessing emitter clogging caused by chemical precipitation when using a treated effluent.

\subsubsection{Lateral flushing}

Prevention of emitter clogging is important for the successful operation of a micro irrigation system (Ayars et al., 2007). Flushing of the micro irrigation system is needed to remove particles that accumulate in the lines before they build up to the sizes and amounts that cause clogging problems (Smajstrla and Boman, 1998). Filtration systems do not remove all suspended materials from the water because of the high cost of removing very small particles. Agricultural filters are usually designed to remove only particles larger than about $10 \%$ of the emitter diameter. Therefore, filters do not normally remove clay and silt size particles. Although these particles are small enough to be discharged through the emitters, they can cause clogging problems when large quantities are present (Nakayama et al., 2007). Flushing of irrigation system pipelines is an essential part of the maintenance program required for long-term success with micro irrigation, flushing will prevent accumulation of small particles and their buildup to size that can plug emitters (Smajstrla and Boman, 1998).

Irrigation laterals are flushed by opening the ends of the lines during operation and allowing water to freely discharge, carrying particulate matter along. The goal of flushing is to discharge water at sufficient velocity so that any particulate matter will be suspended and removed from the system with the flush water (Smajstrla and Boman, 1998). Flushing operation on should continue until the collected water appears sufficiently clean or until no improvement in clarity is observed. 
The duration of flushing depends on many factors, especially the water quality and system design. Before a system is installed, it is difficult to accurately estimate the time required to adequately flush a pipeline (Smajstrla and Boman, 1998). This observation normally only requires a short time and usually only a minute or two is sufficient (Nakayama et al., 2007) because the debris mainly accumulate at the end of the pipeline near the flush value (Smajstrla and Boman, 1998).

Flushing must be done at a suitable velocity to dislodge and transport the accumulated sediments (Pitts et al., 1990; Adin and Sacks, 1991; Ravina et al., 1992; Nakayama et al., 2007). A minimum flow velocity of $0.3 \mathrm{~m} \mathrm{~s}^{-1}$ is needed for flushing of lateral lines as recommended by (ASAE standards, 2001). However, Hills and Brenes (2001) recommended a flushing velocity within the drip line not smaller than $0.5 \mathrm{~m} \mathrm{~s}^{-1}$ to assure that all particles are removed.

\subsubsection{Distribution uniformity}

Distribution uniformity is considered an important measurement for showing the efficiency degree of micro irrigation system. The uniformity is a measurement of the nonuniform pattern of emitter flow of a micro irrigation system $\mathrm{Wu}$ et al., (2007). Water application uniformity can be affected by the hydraulic design, topography, operating pressure, pipe size, emitter spacing and emitter discharge variability.

\subsubsection{Determination of distribution uniformity}

Several methods such as FAO method (Vermeiren and Jobling, 1986; ASAE method (ASAE Standards, 2001). and the ITRC of California Polytechnic State University method Burt, (2004). were developed to determine system uniformity. Each one is based on different concepts, Vermeiren and Jobling (1986) describing the uniformity of drip irrigation systems using "emission uniformity" team (EU). However, Burt (2004), utilized the distribution on uniformity team (DU) term even both are computed with the same formula. Burt (2004) explained the main reasons to use the term DU as following:

- The term of EU refers only to uniformity of emitters on a single new lateral. Further more accounting for, no more, the manufacturing and pressure variations. On the other hand, EU does not account for factors such as unequal drainage and uneven spacing that DU takes into consideration.

- EU was reserved only for drip / micro irrigation system. However, the same uniformity definition should be applicable for furrow, drip and sprinkler systems.

Therefore, the ITRC of California Polytechnic State University method considered in its calculation program the pressure differences between emitters, uneven spacing, unequal drainage and other factors that would cause flow rate differences among emitters (Burt, (2004). The unequal drainage would be caused when a drip/micro system is shut off and some emitters continue to drain while the other emitters have stopped discharge. On the other hand, the ASAE method use the statistical uniformity term $\left(U_{s}\right)$ for describing system uniformity (ASAE Standards, (2001). This method takes into consideration the actual emitter discharge coefficient of variation $\left(\mathrm{V}_{\mathrm{gs}}\right)$ that may be affected due to the overlapping nature of the variance. Under such circumstances, the $\mathrm{V}_{\mathrm{qs}}$ shall be adjusted by dividing it by the square root of the number of emitters per plant to obtain the corrected emitter discharge coefficient of variation and the corrected statistical uniformity $\left(U_{s}\right)$ (ASAE Standards, 2001).

\subsubsection{Acceptability degree of distribution uniformity}

Many researches were made to classify the distribution uniformity degree, Rodriguez, (1990); (ASAE Standards, (2001). The acceptability degree of system distribution uniformity that was classified by Rodriguez (1990), Table (3). Other degree was elaborated by (SAAE Standards 1998) and Burt (2004), Table (4).

Table 3: Acceptability degree for applied micro irrigation system's uniformity (Rodriguez, 1990).

\begin{tabular}{lc}
\hline Rating & DU $_{\text {Iq flow } \%}$ \\
\hline Excellent & $>94$ \\
Good & $86-93$ \\
Acceptable & $80-86$ \\
Unacceptable & $<80$ \\
\hline
\end{tabular}


Table 4: Classification of statistical uniformity (Us) after (ASAE Standards, (2001). and distribution uniformity (DUIq flow) (Burt, 2004).

\begin{tabular}{lcc}
\hline Rating & $\mathbf{U}_{\mathbf{s}} \%$ & DU Iq flow \% \\
\hline Excellent & $>95$ & $>94$ \\
Very Good & $90-94$ & $87-93$ \\
Good & $80-89$ & $75-86$ \\
Fair & $70-79$ & $62-74$ \\
Poor & $60-69$ & $50-61$ \\
Unacceptable & $<60$ & $<50$ \\
\hline
\end{tabular}

Observing a low-quality flow distribution indicates the inefficiency of the micro irrigation system. Understanding the actual reasons and causes that let to this failure would help in solving the problem and improving the distribution uniformity degree.

\section{Concluding statements}

When using SDI systems, it is important to prevent clogging problems before they occur so the benefits of SDI can be reaped for many years. The best prevention plan includes an effective filtration and water treatment strategy. Depending on the water source and its quality, various combinations of sand separation, screen filtration, sand media filtration, chlorination, and acid injection may be required.

Dehghanisanij et al. (2005) reported that, to prevent or reduce emitter clogging induced by biological clogging agents (BCAs), such as algae and protozoa (AP), and to enhance the performance of drip irrigation, two management schemes of without (S1) and with (S2) chlorine injection into the irrigation water at the Tohaku irrigation project, Japan. In a field experiment, six types of emitters on each of six laterals in two similar subunits of DIS, for S1 and S2, were assessed for AP-induced emitter discharge performance. The assessment also included different orifice area (OA), with or without a pressure compensation (PC) system, and with or without built-in filtration area (FA) in the emitters. The discharge from emitters increased with chlorine injection into the irrigation water and with increasing OA and FA but decreased with increasing algae counts. The values for the mean discharge ratio variation (Dra) indicated that the cumulative impact of manufacturing variations $(\mathrm{Vm})$ and that induced by AP and chlorine on emitter discharge was classified as low during the irrigation season when chlorine was injected into the irrigation water (S2). The values for the statistical uniformity coefficient (Uc) were higher than $93 \%$ for both S1 and S2, indicating that the uniformity of emitter discharge along a lateral was high. Due to the reduction in emitter discharge induced by AP, the clogging was uniform along a lateral. The values for field performance variation (Vf) along a lateral were in the order S1 > S2 for each emitter. The values were classified low to medium, particularly in PC emitters

Several researchers Adin and Sacks, (1991); Bucks et al., (1979); Ford, (1978); Ravina et al., (1992); Sagi et al., (1995). Reported that, drip irrigation can be a highly efficient method of supplying water and nutrients to plants, but this depends greatly on maintaining a uniform water application. When small to medium size reservoirs are fed by drainage from intensive animal husbandry, agriculture, and urban areas, a potential exists for the growth of biological clogging agents (BCAs) such as algae, bacteria, and protozoa in such water bodies. When such water is used in drip irrigation systems (DIS), the major problem is that the emitters are vulnerable to clogging by effluent constituents (Adin et al., 1989; Ravina et al., 1992). The impacts of BCAs on reductions of emitter discharge and uniformity of DIS have been studied Adin et al., (1989); Gilbert et al., (1979); Ravina et al., (1992). Other works Adin and Sacks, (1991); Hills and Tajrishy, (1995) have shown that in addition to BCAs and solute chemicals of water, the severity of clogging depends on manufacturing quality of emitters, such as type of emitter and its dimensions, emitter water flow cross-sectional area, path length, flow velocity, and pressure compensation. Chlorination is the least expensive treatment for controlling microbial activity (English, 1985). A few studies have been carried out on the use of chlorine for preventing clogging by BCAs. From these studies, chlorine can be applied either continuously or by sequential pulses of relatively low chlorine concentration (1 to $20 \mathrm{mg} \mathrm{L}-1)$ aimed to prevent biofilm development (Rav-Acha et al., 1995; English, 1985). Feigin et al. (1991) recommended a free residual chlorine concentration of 1 to $2 \mathrm{mg} \mathrm{L}^{-1}$ at the end of a distribution line for continuous disinfection of irrigation water(Tajrishy et al., 1994) evaluated an activated sludge wastewater treatment plant for use in drip 
irrigation with interdependent effects of chlorination and filtration. They observed that sand media and screen filters, along with a single dose of $2 \mathrm{mg} \mathrm{L}-1$ free residual chlorine during the last hour of each irrigation cycle or a constant concentration of $0.4 \mathrm{mg} \mathrm{L}-1$ free residual chlorine in the emitter discharge, were effective in preventing biofilm formation in emitters. Drippers can also be filled with a high chlorine concentration of 500 to $1000 \mathrm{mg} \mathrm{L}-1$ for $24 \mathrm{~h}$ to break down clogging aggregates that have already been formed in the emitters English, (1985); Rav-Acha et al., (1995). Nakayama and Bucks (1986) discussed the principle of chlorination and the various types of chlorine sources for DIS. Liquid sodium hypochlorite $(\mathrm{NaOCl})$ is the easiest form of chlorine to handle and is the type most often used to control BCAs in drip irrigation. Mixing liquid sodium hypochlorite $(\mathrm{NaOCl})$ in water results in the formation of hypochlorous acid $(\mathrm{HOCl})$ and hydroxyl ions $\left(\mathrm{OH}^{-}\right)$, a reaction that raises the $\mathrm{pH}$ of the water. Hypochlorous acid $(\mathrm{HOCl})$ is the effective agent that controls the bacterial growth and is more effective at lower pH (Clark and Smajstrla, 1999; Keller and Bliesner, 1990; Nakayama and Bucks, 1986). In spite of the above research, there is still no specific guideline for applying chlorine into irrigation water ( $\mathrm{Rav}^{-}$Acha et al., 1995). It has been reported that the application of low chlorine concentration might, in some cases, reduce clogging, while in other cases it might aggravate the situation by releasing clogging constituents that were previously stuck to the pipe wall (Rav-Acha et al., 1995; Coelho and Resende, 2001). Several factors determine the overall effectiveness of chlorine addition, such as condition of water (temperature, $\mathrm{pH}$, chemical characteristics, and suspended solids, contact time between chlorine and algae, nature and density of algae, and emitter specification (Hills and Brenes, 2001; Ravina et al., 1997; Tajrishy et al., 1994). Site-specific management to prevent emitter clogging, where BCAs is a serious hazard for stability and endurance of irrigation network, is therefore necessary

Filtration equipment may be the single item of greatest cost when installing the SDI system. Resist the temptation to "cut corners." Good filtration will pay for itself by avoiding the chemical treatments, labor, or extra effort that are otherwise required to fix a system damaged because it was not adequately maintained. Despite our filtration efforts, some materials will not be removed and will find their way into the drip line. To prevent the accumulation of those materials in the drip line and the resultant emitter clogging, the drip lines should be flushed occasionally. Flow meters and pressure gauges should be checked periodically to assure that the system is operating correctly. If measured flow rates and pressure distributions indicate problems in the system, some reconditioning may be possible with chemical injection (including chlorine shock treatments), flushing, and other steps.

Profit margins for crops typically grown in the Great Plains are not as high as the profit margins for fruits and vegetables traditionally grown with SDI systems. To make SDI systems in the Great Plains economically more viable, they must have a long life. Prevention of clogging is therefore critical to the successful and economical use of SDI in the Great Plains.

\section{Influence of sewage irrigation on soil properties}

Soil is not only the base for supporting plant both growth and breeding, but also the foundation of human agricultural production (Killham, 1994; Molles, 2008). All kinds of human agricultural production activities are mainly carried out in the soil, and abundant agricultural products are acquired directly or indirectly from it. Soil is located in the interface of the atmosphere, lithosphere, hydrosphere, and biosphere, participating in a variety of processes involving physics, chemistry and biochemistry, and becoming the crucial location for nutrient cycling and energy flux (Killham, 1994; Huang, 2000). Its existence provides a relatively stable survival and procreation environment for aboveground vegetation and underground microorganisms (Li et al., 2000). In China, untreated sewage is often used directly for farmland irrigation in agricultural production. For substances dissolved in sewage, there are mainly four approaches of transference after migrating into the soil (Wang and Lin, 2003, Zeng and Zhu, 2004, Abou seeda et al., $(2019,2020)$. Some of them would gradually be reduced by the soil selfpurification; others would be adsorbed and retained in the soil layer; the crops could absorb some of them, and the rest would enter aquifers following water infiltration (Qadir et al., 2010; Keesstra et al., 2012; Abou seeda 1984; Abou seeda etal. 1997). Soil, to some extent, has the capacity to clear and degrade pollutants via metabolism through microorganisms, increasing some nutrient content and fertility in the soil (Abou seeda et al., (1997, 2020). However, long-term irrigation using sewage that does not conform water quality standards, allows infiltration of organic pollutants, heavy metals, solid suspended particles and bacteria microbes into the soil (Abou seeda et al. 1995,1997), Rusan et al., 
2007; Zeng et al., 2007; Fatta-Kassinos et al., 2011; Meng et al., 2016). However, soil capacity of self-purification, causing serious soil pollution and giving rise to some changes of soil physical, chemical and biological characteristics.

\subsection{Effects on soil physical characteristics.}

Prolonged of sewage water for irrigation may damages and disturbed the balance of nature, causing ecological deterioration on farmlands, Abou seeda (1987), Abou seeda et al., (1984) (WielShafran et al., 2006). Gradually effect on soil physical properties Abou seeda (1987),(Wang and Lin, 2003). Soil bulk density is one of the important indicators for measuring the effects on soil physical properties and reflecting on chemical properties. It also reflects on soil compaction ,therefore influencing on soil aeration, of soil water holding and absorption capacities, infiltration, soil erosion resistance ability and solute migration Abou seeda (1987),(Huang, 2000). Soil porosity depends on soil bulk density (Neves et al., 2003). A study on the consecutive irrigation of calcareous soil, Li, (2001), showed that prolonged of wastewater treatments gradually changed significantly soil structure. He also stated that good correlation between Soil porosity as well as bulk density and sewage irrigation time, as longer for irrigation the effectiveness of irrigation gradually affects the soil physical properties. Furthermore, irrigation by wastewater effluents causing soil hardening and a decreasing in soil permeability due to accumulation of organic particles in the soil $\mathrm{Li}$ et al., (2003); Li et al., (2006). Furthermore, a negative impact on soil physical properties by constrains such as organic, fiber and sediments resulting in a degradation of soil permeability and increasing soil compaction (Siebe and Fischer, 1996), Abou Seeda (1987). Consequently, low soil permeability and resistance

For plant roots to penetration, soil aggregate characteristics as well as low yield production (Barber, 1994; Mullins et al., 1994)Abou Seeda, and Verloo. (1986). (Ahmed et al., 1987; Franzluebbers et al., 2000), Hu (2010). Hernández et al. 2015 reported that soil compactness cannot be neglected in future agricultural production. Daniel, (1980); Qin, (2003), showed that Irrigation water is controlled by soil structure and soil texture that playing a vital role in controlling water balance, as well as drainage, Shao et al., (2006). Soil texture playing role for available water (Jia and Fan, 2007). Organic matter accumulation might increase field capacity (Lan et al., 2010; Wang and Lin, 2003; He, 2012).

\subsection{Impacts on soil chemical characteristics.}

Sewage effluents affect soil chemical that affects soil fertility (Bao, 2000). The formation of the soil acidity-alkalinity and its changed depends on leaching and accumulation process (Dheri et al., 2007). The acidity or alkalinity can be more conveniently expressed by the $\mathrm{pH}$ value (Huang, 2000; soil has a certain buffer capacity, and $\mathrm{pH}$ value is relatively stable (Masto et al., 2009). Once the $\mathrm{pH}$ value varies drastically, the soil chemical properties will be changed accordingly, which affects directly the existing form, transformation and availability of soil nutrients (Ma and Zhao, 2010). Soil pH changes are related to types of irrigation water as well as soil category (Wan et al., 2015). Wan et al. (2012) showed that the prolonged of wastewater effluents, $\mathrm{pH}$ value gradually decrease. On the other hand, Xia et al. (2011) showed that increasing $\mathrm{pH}$ value by wastewater effluents from paper-making factories making a moderately degraded saline-alkali soil. It was also found that there was no obvious effect on the soil $\mathrm{pH}$ of a vegetable field when sewage came from a livestock breeding enterprise (Zhang et al., 2011). The different degrees of ammonification and nitrification processes of the soil organic matter, anaerobic organic matter decomposition, and release and enrichment of metal ions (Dheri et al., 2007; Rusan et al., 2007) could explain the reason for the fluctuation of the $\mathrm{pH}$ value.

Organic matter is correlated to a soil fertility (Rattan et al., (2005). Accumulation of organic matter is not only closely related to natural environmental conditions, but depends on the input of organic matter through wastewater irrigation (Qin, 2003; Shao et al., 2006), and can increases soil fertility. However, the amplitude of this increase showed great agro type and spatial differences (Xue, 2012). Irrigation by eutrophic sewage showed that the soil organic matter content of sandy and loamy soils increased significantly, by about $2.73 \mathrm{~g} / \mathrm{kg}$ to $5.38 \mathrm{~g} / \mathrm{kg},(97.1 \%)$, particularly in loamy soil. However for the sandy gradually increased from $0.85 \mathrm{~g} / \mathrm{kg}$ to $1.16 \mathrm{~g} / \mathrm{kg}(36.5 \%)$ (Lanet al., (2010). Comparable differences in the content of soil organic matter also existed when considering increments of soil depth within the soil profile. Extremely significant increases in the content of soil organic matter were easily discovered within the first $20 \mathrm{~cm}$ of the topsoil, while the increase levels were significantly 
reduced with increases in soil depth (Hu, 2010; Abou seeda (1987). Furthermore, much effort focused in maintaining the global carbon balance on the soil organic matter. Rattan et al., (2005); Zhang et al., (2008) stated that cumulative effects of soil organic matter due to wastewater effluents of soil organic carbon in the global carbon circulation.

Nitrogen is an essential nutrient for crop growth, and development (Masto et al., 2009). A study of irrigation using aquaculture wastewater for a long time showed that nitrogen accumulation in and contents soil increased significantly, greater than that of the untreated farmland for more than 12 years (Zhang et al., 2011). Similar trend were noticed by Abou seeda (1987), stated that application of wastewater effluents stimulate the accumulation of nitrogen in soil.. An obvious eutrophication due to soil irrigated with sewage water effluent for long period alkali-hydrolysable nitrogen content increased significantly in each study soil layer, especially in the soil surface and its content could reach 8.26 $\mathrm{mg} / \mathrm{kg}$, than the average $(\mathrm{Hu}, 2010)$. At the same time, nitrogen accumulation in the soil was significantly affected by nitrogen mobility and irrigation infiltration (Wiel-Shafran et al., 2006). The accumulation of $\mathrm{NO}_{2}{ }^{-}$and $\mathrm{NO}_{3}{ }^{-}$because of water eluviation caused groundwater pollution (Zhang et al., 1996). Sewage irrigation had a lower impact on $\mathrm{NH}_{4}+$ existing in deep soil and groundwater. However long-term sewage irrigated soil greatly influenced the $\mathrm{NO}_{3}^{-}$concentration, causing groundwater pollution (Liu and $\mathrm{Lu}, 2002$ ).

Phosphorus is one of the three essential nutrients for plants. It not only constitutes the components of many important compounds in plants, but also participates in various metabolic processes in plants (Abou seeda etal., 1997; Dalai, 1977; Redding et al., 2002; Marschner et al., 2007; Abou seeda et al. 1997; Abou seeda etal., 2019 and Abou seeda 2020. The studies on forestlands found that the total phosphorus had significantly increased in the surface soil at $(0-40 \mathrm{~cm})$ layer due to long irrigation of wastewater (Hu et al., 2010; Hu et al., 2012). Comparable results were observed in soil irrigated with swine wastewater, showed that phosphorus accumulated in the plowing layer $(0-40 \mathrm{~cm})$ and gradually increased with the time of irrigation, Abou seeda (1987), (Yu, 2009). Reddling et al., (2005), discovered soil available total phosphorus and contents treated with piggery wastewater after anaerobic digestion were significantly higher than those from irrigation wastewater effluents were. Phosphorus levels appeared to be a result of excessive accumulation in the topsoil layer.

Potassium is also a major nutrient in higher plants; together with nitrogen and phosphorus, they are known as the three essential factors for plant nutrition. Available potassium refers to the potassium that is easily absorbed by the plant and becomes the main diagnostic index of soil fertility (Huang, 2000; Qin, 2003; Abou seeda etal., 1997). In studies of $\mathrm{Hu}$ (2010) and Masto et al. (2009), the soil available potassium content increased greatly after sewage irrigation. This was mainly because many nutrients were contained in the sewage, making available potassium enrichment possible in the soil surface. The content of total potassium in soil could also be improved by the application of molasses alcohol water in the sewage irrigation and gradually increased the total soil potassium content, which improve soil fertility $(\mathrm{Xu}, 2007)$.

Heavy metals from sewage effluents can be adsorbed and precipitated in soil due to their solubility product. Most of heavy metal are concentrated in the soil, causing heavy metal pollution. It has become the most serious problem for human health (Liu et al., 2005; Mapanda and Mangwayana, 2005; Wan et al., 2015 Abou seeda et al., 2019,2020). Metal distribution was homogeneous, but heavy metal spatial distribution has shown important differences (Liu et al., 2005; $\mathrm{Hu}$ et al., 2006; Khan et al., 2008; Abou seeda 1987) reported that sewage water effluents application gradually increased the accumulation of heavy metals in the upper soil layer. Cao (2014) concluded that heavy metal elements concentrated in the soil within the first $50 \mathrm{~cm}$ depends on soil texture. Heavy metal content was related to type of soils Silt soil was not favorable for heavy metal accumulation as well as sandy soil. The main enrichment of heavy metals was reported in loamy soil (Wang and Lin, 2003). The degree of heavy metal content in soil is related to the prolonged irrigation as well as the of heavy metal content in effluents, Abou seeda (1975), Abou seeda etal (1997), Liu et al., (2005); Rattan et al., (2005). Wang et al., (2008) found that long-term, sewage water application gradually increased and sometimes exceeded the standards. This is $\mathrm{Cu}, \mathrm{Pb}, \mathrm{Zn}, \mathrm{Cd}, \mathrm{As}, \mathrm{Hg}, \mathrm{Cr}$ and other harmful substances seriously exceeded the limits of soil capacity. Five toxic metals $(\mathrm{Cd}, \mathrm{Cr}, \mathrm{Cu}, \mathrm{Zn}$, and $\mathrm{Pb})$ increased during sewage irrigation and pollution with $\mathrm{Cd}, \mathrm{Cu}, \mathrm{Zn}$, and $\mathrm{Pb}$ was exacerbated in soils (Sun et al., 2006; Wang et al., 2006). Ultimately, these heavy metals are dangerous to human health through various food chains (Loska et al., 2004). 
In addition to heavy metal pollution in soil, there exist various other degrees of organic pollutants in some sewage irrigation areas (Qadir et al., 2010). Organic pollutants, such as aromatic hydrocarbons, phenols, and organic chlorines are easily discovered in industrial wastewaters (Tian et al., 1993). A research by collecting seven different soil samples depths irrigated by wastewater. Sewage diversified and were extremely complicated; they were pollutants as plasticizer, such as phthalate esters, skatole, sterols, polycyclic aromatic hydrocarbons. Polycyclic aromatic hydrocarbons were found in soil irrigated with wastewater effluents, which penetrated into the groundwater causing groundwater pollution (Du et al., 2010). A survey in the Shenyang and Fushun sewage irrigation area, the China's largest oil wastewater irrigated area, showed that the accumulation of toxic substances because of the petrochemical industrial sewage was serious (Abou seeda et al., 2017). Among the toxic substances, the aromatic hydrocarbons represented an important proportion, and the carcinogens benzene and pyrene were severely exceeded (Zhang et al., 2003). The sensory indicators of rice produced in this region were extremely poor, with strong smell from oils and aromatic compounds (Fang, 2011).

\subsection{Influence of soil microorganisms and enzyme activities.}

Soil microorganisms, as an important part for maintaining soil quality, participates in most of soil biological and biochemical activities, and are sensitive to reflect changes of soil quality health (Stenberg, 1999). The quantity, composition and activity of soil microbial population are a dynamic process; environmental changes and the number of microbial living cells constitute one of the most sensitive biological indicators (Li et al., 2005). Sewage effluents cause a change of microhabitat and, having a great effect on soil microbial activities (Zhang et al., 2008). Soil bacteria, fungi and actinomycetes can be used to reflect the total amount of soil microorganisms. Which play a significant role on soil organic and inorganic matter (Aleem et al., 2003). The number of bacteria and actinomycetes in the soil showed a descending trend after long-term sewage irrigation. However, fungi increased slowly (Ge et al., 2009). Total nitrogen showed very significantly positive correlations with bacteria, nitrogen-fixing bacteria, and phosphorus bacteria (Zhang et al., 2007; Zhang et al., 2008). In the meantime, the way of sewage irrigation application affected number of soil microorganisms (Heidarpour et al., 2007). A series of studies by Oron et al. (1999) displayed that soil surface humidity affected the total number of soil bacteria after sewage irrigation. Subsurface or underground drip irrigation was adopted; the total number of bacteria of subsurface drip irrigation was much higher than that of the underground, (Oron et al., 1995; Oron et al., 1999).

Soil enzymes are active substances found in the soil, primarily coming from the soil microbes and plant root secretions and enzymes released by the decomposition of animal and plant residues (Burns and Dick, 2002; Cao et al., 2003). Common enzymes mainly include oxidoreductases, hydrolytic enzymes, crack enzymes and transferation enzymes, all of which participate in and promote a large proportion of organic substance transformation and material circulation by soil ecological processes (Zhang et al., 2011). Li et al., (2005) Suggesting that irrigation by petroleum-processed wastewater could stimulate aerobic heterotrophic bacteria and fungi growth in the soil. The total petroleum hydrocarbon content in the soil showed a positive correlation with the soil dehydrogenase, catalase and polyphenol oxidase activities and a negative correlation with the soil urease activity Other observations were found that soil enzyme activities were influenced by soil nutrients and multiring hydrocarbon pollution, after long-term irrigation by petroleum-processing wastewater. The soil both organic carbon and total phosphorus content showed significant relationships with the dehydrogenase, polyphenol oxidase and urease activities. The content of multiring hydrocarbon was significantly positive correlated with the dehydrogenase, urease, and polyphenol oxidase activities (Zhang et al., 2007; Zhang et al., 2008; Liu, 1996). Many studies have shown indirect influences caused by sewage irrigation such as soil secondary salinization in calcareous drab soil, which lead to constrain enzyme activities, causing a decline in soil environmental quality $(\mathrm{Li}, 2001)$.

\subsection{Implications for sewage irrigation development in the future}

For the current development of sewage irrigation, governors must clearly realize that wastewater discharge itself is a guarantee to replace the water scarcity for grain production, for the population demands for food. On the other hand, the adverse effects brought by the sewage irrigation were removed completely. Therefore, any research and development involving sewage irrigation have to consider 
carefully the current situation. We suggest that four aspects should be taken into account for achieving a safe and efficient utilization of wastewater irrigation in agro management technique.

\subsection{Strict control of the pollution and supervising systems.}

At present, the first question for sewage irrigation in China is to solve the quality problem gradually. Starting from the sewage source, water quality monitoring should be much greater, and water quality of the wastewater entering the farmland should be strictly controlled (Engineering, 2000; Yang, 2000; Qadir et al., 2010; Abou seeda 1987; Abou seeda et al., 2019). Contaminated water that seriously exceeds the threshold levels should be forbidden from discharging and utilization. Currently, governors always adopt an attitude towards removing responsibility of supervision and administration of sewage in the practice. Therefore, a management system of sewage irrigation should be established and implemented urgently. It has to explicit the appropriate responsibilities and embodiment at different stages of sewage discharge, disposal and irrigation (Zeng and Zhu, 2004; Shi et al., 2014,Abou seeda et al., $(1984,1986)$. For the companies and individuals in the wastewater irrigation area, awareness of environmental protection should be increased (Rattan et al., 2005; Wan et al., 2015).

\subsection{Optimization and avoiding of sewage irrigation, using a single-type-sewage for a long time.}

Some effective methods for sewage irrigation techniques through several decades of practicing, include oxidation pond purifying wastewater treatment, and mixed irrigation between wastewater and clear water (Hong et al., 2011; Abou seeda et al., 1992). However, the flooding irrigation mode is the most common adopted in the vast area of sewage irrigation. On the one hand, it wastes many valuable sewage resources. At the same time, however, it causes serious soil pollution Zhang et al., 2005; Abou seeda et al., 1992; Abou seeda, 1995). Thus, the current model of sewage irrigation should be changed and optimized, combining agricultural water-saving irrigation with sewage pretreatment, and developing underground, aerated drip sewage irrigation. Considering the different crop growth stages, edible parts and contaminants in wastewater irrigation, sewage irrigation time and quantity need to be allocated reasonably, reducing the effect of sewage irrigation on crop growth and human health (Oron et al., 1995; Oron et al., 1999; Abou seeda, 1997).

\subsection{Control of sewage irrigation to local conditions and protecting groundwater resources.}

Because of improper irrigation facilities and methods, unscientific irrigation systems and low management levels, field irrigation efficiency is low and percolation towards deep soil layers is serious (Liu and Xu, 2002; Abou seeda 1995). Failing in making a proper sewage irrigation or irrigation by untreated sewage easily gives rise to infiltration of pollutants in the soil, endangering the security of drinking water and even forming inverse funnels of sewage, which pose a threat to deep groundwater. Once groundwater is contaminated, it will be difficult to recover, and the consequences will be severe. It seems reasonable to assume that it will not be suitable for sewage irrigation for some unadaptable wastewater irrigation areas such as those with strong soil permeability Abou seeda (1984),, Abou seeda et al., (1997), high underground water level, aquifer outcrops and centralized drinking water sources, which will easily lead to groundwater pollution and be unfavorable to human health (Zhou, 2002; Qadir et al., 2010). Therefore, it is appropriate to adjust measures to local conditions for sewage irrigation, and reduce the environmental risks caused by sewage irrigation ( Abou seeda etal., 1997; Abou Seeda et al., 2017).

\subsection{Adsorption and degradation of soil substances by some plant and microbe.}

In the technical field of heavy metal contaminated soil repair, phytoremediation is highly favored for its advantages such as an excellent reinforced effect, low cost and high environmental benefits (Nie et al., 2016) Abou Seeda et al., 2019; Abou Seeda et al., 2020).At the same time, microorganisms could either fix heavy metal ions through their metabolic functions or convert toxic heavy metal ions into non-toxic or low-toxic conditions, Abou Seeda et al., (2017) (Li et al., 2015) Abou Seeda, et al., (2005). Abou seeda et al., (2020), stated that hyperaccumulators could be introduced to repair soils contaminated by sewage irrigation adopting their own strong absorption ability for some heavy metals and non-heavy metal toxicity Furthermore, the function of microbial selective absorption was jointly utilized to establish the system of plant-microbial repairment, improving the efficiency of heavy metal pollution soil restoration (Rajkumar et al., 2010). 


\section{Risks from wastewater reuse for irrigation in agriculture \\ 4.1. Microbial risks}

Using wastewater in agriculture may pose substantial risks to public health, food safety and environmental quality (Scott et al., 2004; Scheierling et al., 2010). As wastewater treatment facilities in most developing countries are non-existent or function insufficiently, farmers in many of these countries use untreated or partially treated wastewater. Partially treated wastewater contains high concentrations of pathogens and disease agents including bacteria, nematode eggs, viruses and protozoa (WHO, 2006).These pathogenic organisms have been implicated as the most important cause of chronic gastro enteric diseases including diarrhea and outbreaks of acute diseases such as cholera in Jerusalem and Dakar and typhoid in Santiago. (Owusu et al., 2012; Scott et al., 2004). Hussain et al. (2002) Reported that in Pakistan, farmers who use wastewater have a higher rate of diarrhoeal disease incidence than farmers using groundwater. Many of these pathogens have significant resistant to conventional biological treatment processes.

Therefore, these pathogens are difficult to remove and can survive for a long time in soil or on crop surfaces and may consequently be transmitted to humans or animals (WHO, 2006). A study conducted in Dakar in Senegal indicated that farmers who mainly use untreated wastewater are more likely to have a higher rate of intestinal parasites compared to those who use diluted wastewater (Owusu et al., 2012). Skin diseases are also another problem associated with direct exposure to wastewater (Bos et al., 2010; Owusu et al., 2012). In Cambodia and Vietnam, skin disease such as dermatitis has been attributed to contact with untreated wastewater. Rice farmer in India has also reported problems such as blistering and itching in hands and feet, and urban vegetable farms in Ghana (Bos et al., 2010).

Risks associated with wastewater are not limited to agricultural workers only but can be observed in workers families and nearby communities through exposure to wastewater and the consumption of produce grown using wastewater especially when eaten uncooked and also produce handlers (Bos et al., 2010; Owusu et al., 2012). Also, evidence provided by (WHO, 2006) suggest that both farmers' families and the consumers of wastewater-irrigated crops more frequently contract helminth infections.

\subsection{Chemical risks}

Microbiological risks, the practice of wastewater reuse can pose a range of other potential risks to human health and environmental quality because of a great variety of toxic organic, and inorganic chemicals that are present in the wastewater (Qadir et al., 2010; Abou seeda 2019). In general, the key issues relating to the chemical constituents of wastewater and its subsequent use in agriculture are excessive levels of salt, heavy metals Abou seeda et al., (1997), excessive nutrients and toxic organic and inorganic compounds:

\subsection{Excessive levels of Salt}

Wastewater usually has a higher concentration of total dissolved solids and major ions and higher electrical conductivity than fresh water especially in regions with a hot climate where there is a long dry season and a high rate of evaporation. These dissolved solids and ions originate from many sources such as detergents and washing material, chemicals used during the treatment process and other sources (Toze, (2006a,b; Qadir and Scott, 2010; Muyen et al., 2011; Becerra-Castro et al., 2015; Abou Seeda et al., 2019). Abou seeda (1984) reported that application of wastewater treatments gradually increased the salinity levels, similar trend were noticed and ranged from slightly saline (with electric conductivity EC $0.75 \mathrm{dS} / \mathrm{m}$ ) to saline water (EC $>3 \mathrm{dS} / \mathrm{m}$ ) while sodicity (SAR) levels were between 1.9 and 20.8 (Qadir and Scott, 2010). Abou seeda et al., (1997),Abou seeda et al., (2019),they reported that prolonged of wastewater treatments could lead to salt accumulation in the soil layers observed in the topsoil due to evaporation. It can also cause elevated concentrations of exchangeable sodium cations $\left(\mathrm{Na}^{+}\right)$and a higher exchangeable sodium percentage (ESP) (Qadir and Scott, 2010; García and Hernández, 1996; Rietz and Haynes, 2003; Hamilton et al., 2006). For example, a study conducted in Jordan shows that wastewater reuse increased soil salinity two to three times compared to a control site (Al-Zu'bi, 2007). Also long-term wastewater reuse (up to 80 years) in the Valley of Mezquital in Mexico as well as in Egypt led to increasing soil salinization, especially Na saturation (Friedel et al., 2000; Abou seeda (1984). In arid and semi-arid Western USA shows that application of wastewater exhibited a $187 \%$ higher EC and $481 \%$ higher sodium adsorption ratio (SAR) as compared with irrigated soil with fresh water (Qian and Mecham, 2005). Similar observation noticed in El Gabal El Asfar, Abou 
seeda (1984), Abou seeda et al., (1997). Muyen et al., (2011) stated that annual application of 1000 $\mathrm{mm}$ of wastewater with $500 \mathrm{mg} / \mathrm{l}$ of total dissolved solids (TDS) might lead to an additional $5 \mathrm{t} / \mathrm{h} / \mathrm{year}$ of salt in the soil unless it is properly drained. Increasing soil salinity has significant effects on the hydraulic properties, degradation of soil structure and can result in a decrease in soil productivity and crop yields. High concentration of sodium (Na), boron (B), and chloride (CL) may affect plant growth through adverse osmotic effects, phytotoxicity or plants nutrient deficiency (Qadir and Scott, 2010).

\subsection{Excessive Nutrients}

Wastewater commonly contains high concentrations of nutrients in the form of nitrogen, phosphorus and potassium. Nutrient concentration will vary significantly, depending on whether untreated, diluted or treated wastewater is used Abou Seeda et al., (2019), nutrients concentration were gradually differed in untreated wastewater and in treated effluent from secondary and advanced tertiary processes. Although the nutrient supply capacity is considered the main driver for wastewater reuse in agriculture, nutrient concentrations in wastewater can reach levels that are excessive. This could result in possible negative effects of nutrients oversupplying especially nitrogen and phosphorus. Oversupply of nitrogen through wastewater reuse could lead to excessive vegetative growth, delay in maturity and reduced crop size and quality that will result in low economic yield (WHO, 2006, Hamilton et al., 2005, Qadir and Scott, 2010, Chen et al., 2013a), Abou seeda et al., (2019). Nitrate leaching is another concern associated with excessive nitrogen in wastewater that may lead to contamination of groundwater causing health problems including methemoglobinemia in neonates (WHO, 2006, Hamilton et al., 2005; da Fonseca et al., 2007; Gwenzi and Munondo, 2008, Knobeloch et al., 2000; Candela et al., 2007). Furthermore, excessive nitrogen and phosphorous in wastewater may impact soil microbial communities, in particular, the microbial activities associated with cycling of these elements (Becerra-Castro et al., 2015). The excess of nutrients can disturb the autochthonous soil microbial communities, for example, the accumulation of inorganic- $\mathrm{N}\left(\mathrm{NO}_{3}-\mathrm{N}\right.$ and $\left.\mathrm{NH}_{4}-\mathrm{N}\right)$ in soils could affect the microbial catabolic activity, especially the biodegradation of recalcitrant carbon compounds that are present in soil (DeForest et al., 2004; Ramirez et al., 2012). Both nitrogen in form of $\mathrm{NO}_{3}-\mathrm{N}$ and $\mathrm{P}$ can reach surface water via drainage systems or soil erosion and cause eutrophication or toxicity in other habitats (Hamilton et al., 2005; WHO, 2006; Wu, 1999).

\subsection{Toxic organic compounds and emerging contaminants}

Wastewater contains toxic organic compounds such as organic pollutants e.g. pesticides (DDT, 2,4-D, Aldrin), industrial compounds (phthalates PCBs, non-ionic detergents), disinfection byproducts, synthetic and natural hormones, pharmaceuticals and personal care products ( $P P C P S$ ) (WHO, 2006; Onesios et al., 2009; Bolong et al., 2009; Muñoz et al., 2009; Cizmas et al., 2015). Organic pollutants are difficult to detect as well as remove. Furthermore, they vary considerably in their form and their mechanism of actions that makes the identification and evaluation of these compounds a unique challenge (Boulaletal., 2013). These toxic pollutants may have carcinogenic, teratogenic and mutagenic effects and many of them are Endocrine Disrupters Chemicals (EDCs). Such chemicals may interfere with some hormone functions in both animals and humans. WHO, (2006), Qadir et al., (2010), Boulal, et al., (2013), Cizmas et al., (2015), Wu et al., (2015). However, their negative effects on human health are still being debated Boulal, et al., (2013) WHO, (2006), Toze, (2006a and b) Onesios et al., (2009), Bergman et al., (2013), relationships have been identified between endocrine disruptors and increased incidences of endocrine-related cancers such as breast, ovarian, prostate, testicular and thyroid cancer (Cizmas et al., 2015; Bergman et al., 2013). Abnormalities, altered immune function and population disruption due to exposure to these pollutants have also been observed in birds, reptiles, mammals, amphibians and invertebrates (WHO, 2006; Boulal, et al., 2013; Bergman et al., 2013). Many EDCs and PPCPs could persist in the environment and may accumulate in irrigated soils or eventually reach surface water or groundwater, leading to human exposure through drinking water (WHO, 2006; Chen et al., 2013a; Chen et al., 2011). From the data available in the literature, soil systems are better equipped than watercourses for the degradation of many of these compounds, with mechanisms including microbial degradation or adsorption by soil organic matter (Qadir et al., 2010; Chen et al., 2011; Dalkmann et al., 2014; Qin et al., 2015; Abou Seeda et al. (2020,2019). However, some of them such as PPCPS may be taken up by crops or transferred to the edible surface of crops because of irrigation with wastewater or soil that remains on the surface of crops after harvesting (WHO, 2006, 
Wu et al., 2015, 2014). Most of the studies on plant uptake of PPCPs were conducted in greenhouses or in the laboratory and data on the accumulation of these chemicals in crops irrigated with wastewater under realistic conditions is limited (Wu et al., 2015). However, research findings reported to date would suggest that the potential for these substances to enter edible parts of crops was low under normal field conditions (Wu et al., 2015; Prosser and Sibley, 2015). Several researchers suggests that their effects on crops quality could be negligible (Chen et al., 2011; Wu et al., 2015). The major concerns related to PPCPs are the potential development of antibiotic resistance in soil and water microorganisms because of discharging antibiotics into the environment (Toze, 2006a; Chen et al., 2011; Cizmas et al., 2015; Abou seeda et al., 2020). Currently, considerable uncertainty exists regarding the potential risks of PPCPs and their transformation products to agricultural and environmental health. (Qin et al., 2015; Bergman et al., 2013). However such substances in the environment are generally alarming, their concentration in water sources (Qadir et al. , (2010), furthermore, these chemicals have short effects on environmental due to their half-lives (Toze, 2006a, Chen et al., 2011).

\section{Conclusions}

The demand for potable water resources increases; wastewater is receiving attention as an alternate irrigation source. The incorporation of wastewater use planning into national water resource and agricultural planning is important, especially where water shortages exist. This is to not only protect sources of high-quality waters but also to minimize wastewater treatment costs, safeguard public health and to obtain the maximum agricultural and aqua cultural benefit from the nutrients that wastewater contains. Wastewater use may well help reduce costs, especially if it is envisaged before new treatment works are built, because the standards of effluents required for various types of use may result in costs lower than those for normal environmental protection. The use of wastewater has been practiced in many parts of the world for centuries. Whenever water of good quality is not available or is difficult to obtain, low quality waters such as brackish waters, wastewater or drainage waters are spontaneously used, particularly for agricultural. Unfortunately, this form of unplanned and, in many instances unconscious, reuse is performed without any consideration of adequate health safeguards, environmentally sound practices or basic agronomic and on-farm principles. Authorities, of Health and Agriculture, should investigate current wastewater reuse practices and take gradual steps for upgrading health and agronomic practices. This preliminary survey provides the basis for the clear definition of reuse priorities and the establishment of national strategies for reuse. It should also assign responsibilities and should create capacity for operation and maintenance of treatment, distribution and irrigation systems, as well as for monitoring, surveillance and the enforcement of effluent standards and codes of practice. However, the effects of inappropriate sewage irrigation on soil physical, chemical and biological characteristics in agricultural soils should paid attention to its practical application. Some relevant, proper irrigation facilities and methods, scientific irrigation systems from agriculture and water resource departments, and high sewage management levels are worth applying. The treated liquid municipal wastes by their utilization for irrigation of crops constitute an important mean for saving fresh water for other uses. The use of treated wastewater is encouraged in crops where humans do not come in direct contact with them. Such cases are recreation areas, parks, ornamental plants in pavements. The wastewater contained small percentages of organic charge and various inorganic elements due to its tertiary treatment. The lower growth of plants received wastewater is probably too high chloride concentration of waste. As regards the water consumption, the use of wastewater resulted in saving of fresh water. The interest in subsurface drip as a wastewater distribution system appears to be increased. The applicability of this method should increase for use in wastewater systems, as future research succeeds in establishing proper system sizing criteria and continuing improvements in the reliability of system components.

Wastewater management needs to be approached in a novel way in order to include agricultural demands, socioeconomic and institutional realities, the importance of helping nature to close ecological cycles and, most of all, to include the idea that to improve the quality of life does not necessarily mean the same thing in different regions. This integral approach implies modifying some of the more traditional sanitation concepts in order to achieve a balance between long- and short-term ecological risks and society is pressing needs. 


\section{References}

Abbott J.S., 1985.Emitter clogging-coarse and prevention ICID Bulletin 34(2): 11-20.

Abou Seeda M.A, A.A. Yassen and E.A.A. Abou El-Nour, 2017. Microorganism as a tool of bioremediation technology for cleaning waste and industrial water. Bioscience Research, 14(3): 633-644.

Abou Seeda M.A., A.A. E-Sayed, Yassen A.A. Sahar, M. Zaghloul and A. Khater, 2019. Heavy metals, Sources, Chemistry, risks and best applicable approach for remediation of contaminated soils: A review, Middle East Journal of Applied Sciences, 09 (04): 2706 -7947 ISSN: 2077- 4613.

Abou Seeda M.A., A.A. Yassen, E.A.A. Abou El-Nour, M. Gad Mervat and Sahar M. Zaghloul, 2020. Phytoremediation of heavy metals principles, mechanisms, enhancements with several efficiency enhancer methods and perspectives: A Review Middle East Journal of Agriculture Research, 09(01): 2706-7955 ISSN: 2077-4605.

Abou Seeda, A.A., A.A. Yassen, A. Abou El-Nour, A.A. E-Sayed and A. Khter, 2019. Impacts of Treated Wastewater on Soil and Yield of Sunflower. American-Eurasian J. Agric., and Environ. Sci., 19 (3): 180-189.

Abou Seeda, M. A., 1997. Use of sewage sludge for sustainable agriculture and pollution preservation. III. Treatment of sewage sludge and its effect on chemical characteristics of sludge, soil and some nutrients uptake by Radish, Spinach and lettuce plants. J. Agric. Sci. Mansoura Univ. 22 (10): 3423-3450.

Abou Seeda, M. and M. Verloo., 1986. The chemical characterization of polluted Egyptian soil. Environ. Contam. Inter. Conf. Amst. 321-324.

Abou Seeda, M., 1987. Chemical and environmental aspect of sewage sludge application on Egyptian soils. Ph.D. Thesis. Belgium, Gent.

Abou Seeda, M., A. Khater and E.M. Khaled, 1997. Use of sewage sludge for sustainable agriculture and pollution preservation. I. Composting of sewage sludge. J. Agric. Sci. Mansoura Univ. 21 (11): 4179-4193.

Abou Seeda, M., M. Verloo and M. DeBoodt., 1984. Influence of prolonged sewage sludge application on the uptake of micronutrient and chemical properties of some Egyptian soils. Environ. Contam. Inter. Conf. Lond. 232-236.

Adin, A. and G. Alon 1986. Mechanisms and process parameters of filter screens.

Adin, A. and M. Elimelech 1989. Particle filtration for wastewater irrigation. Journal of irrigation and Drainage Engineering, 115 (3): 474-487.

Adin, A. and M. Sacks, 1987. Water quality and emitter clogging relationship in wastewater irrigation. Proceedings of water reuse symposium, Denver, Colorado, USA, 517-530.

Adin, A. and M. Sacks, 1991. Dripper-clogging factors in wastewater irrigation. Journal of irrigation and Drainage Engineering, 117(6): 813-826

Ahmed, H.A.-M., E.S. Gerald, and R.H. Hart, 1987. Soil Bulk Density and Water Infiltration as Affected by Grazing Systems. Journal of Range Management 40: 307-309.

Alam, M. 1996. Irrigation. Subsurface microirrigation. Colorado State University Cooperative Extension Publication No. 4.716. Ft. Collins., 3.

Aleem, A., J. Isar, and A. Malik, 2003. Impact of long-term application of industrial wastewater on the emergence of resistance traits in Azotobacter chroococcum isolated from rhizospheric soil. Bioresource Technology 86: 7-13.

Al-Nakshabandi, G.A., M.M. Saqqar, M.R. Shantnawi, M. Fallad and H. Al-Horani 1997. Some environmental problems associated with the use of treated wastewater for irrigation in Jordan. Agricultural Water Management, 34 (1): 81-94.

Al-Zu'bi, Y., 2007. Effect of irrigation water on agricultural soil in Jordan valley: An example from arid area conditions. Journal of Arid Environments, 70: 63- 79.

Amburgey J. E., and A. Amirtharajah, 2005. Strategic Filter backwashing techniques and resulting particle passage.Environ, Engineering 131(4):535-547

Amirtharajah A., 1988. Some theoretical and conceptual views of filtration. American Water Work Association, 80 (12): 363-46.

Amirtharajah, A. and D.P. Wetstein 1980. Initial degradation of effluent quality during filtration. American Water Work Association, 72(10): 518-524. 
Amirtharajah, A., 1985. The interface between filtration and backwashing. Water Research, 19 (5): $551-$ 588.

Anderson, J., 2003. The environmental benefits of water recycling and reuse. Water supply, 3 (4): 110.

Aronion, R., C. Dlugy, E. Arkhangelsky, S. Shandalov, G. Oron, A. Brenner and V. Gitis 2009. Removal of viruses from surface water and secondary effluents by sand filtration. Water Research, 43 (1): 87-96

ASAE Standards, 2001. S526.2 ASAE stander, soil and water terminology. American society of Agricultural Engineers, St. Joseph, Michigan, USA.

AWWA., 2003. Principals and particles of water supply operations: Water treatment. Third Edition, American Water Work Association, Denver Colorado, USA.

Ayars, J.E. and C.J. Phene, 2007. Automation. In: Lamm F. R., Ayars J. E. and Nakayama F. S.(ed. Microirrigation for crop production: Design, Operation and Management". Developments in Agricultural Engineering 13, Elsevier, Amsterdam, The Netherlands, 259-284

Ayars, J.E., D.A. Bucks, F.R. Lamm and F.S. Nakayama 2007. Introduction. In: Lamm F.R., Stars J.E. and Nakayama F. S. (ed. Microirrigation for crop production: Design, Operation and Management. Developments in Agricultural Engineering 13, Elsevier, Amsterdam, The Netherlands, 1-26.

Bao, S.D., 2000. Soil and Agricultural chemistry analysis, China Agriculture Press, Beijing.

Barber, R.G., 1994. Persistence of Loosened Horizons and Soybean Yield Increases in Bolivia. Soil Science Society of America Journal 58: 943-950.

Becerra-Castro, C., A.R. Lopes, I. Vaz-Moreira, E.F. Silva, C.M. Manaia, and O.C. Nunes, 2015. Wastewater reuse in irrigation: A microbiological perspective on implications in soil fertility and human and environmental health. Environment International, 75: 117-135

Bergman, Å., J.J. Heindel, S. Jobling, K.A. Kidd, R.T. Zoeller, and S.K. Jobling, 2013. State of the science of endocrine disrupting chemicals 2012: an assessment of the state of the science of endocrine disruptors prepared by a group of experts for the United Nations Environment Programme and World Health Organization, World Health Organization

Blumenthal, U.J., A. Peasey, G. Ruiz-Palacios and D.D. Mara 2000. Guidelines for wastewater reuse in agriculture and aquaculture: recommended revisions based on new research evidence. Task No. 68 Part 1. Water and Environmental Health at London and Loughborough, Loughborough University, Leicestershire, UK.

BOE., 2007. Real Decreto 1620/2007, de 7 de Diciembre, por el que se establece el régimen jurídico de la reutilización de las aguas depuradas, 294: 50639-50661

Bolong, N., A.F. Ismail, M.R. Salim, and T. Matsuura, 2009. A review of the effects of emerging contaminants in wastewater and options for their removal. Desalination, 239: 229-246

Bond, W.J., 1998. Effluent irrigation : An environmental challenge for soil science. Australian Journal of Soil Research, 36 (4): 543-555.

Bos, R., R. Carr, and B. Keraita, 2010. Assessing and mitigating wastewaterrelated health risks in low-income countries: An introduction. Wastewater irrigation and health: Assessing and mitigating risk in low-income countries, 29-47.

Boulal, H., L. Sikaoui, and M. El Gharous, 2013. Nutrient management: a new option for olive orchards in North Africa. Better Crops with Plant Food, 97: 21-22.

Brown, L.R., 1995. Who will feed China? Wake-up call for a small planet.

Bucks D.A., F.S. Nakayama and R.G. Gilbert 1979. Trickle water quality and preventive maintenance. Agricultural Water Management, 2 (2): 149-162.

Burt C.M., K. O'Conner and T. Ruehr 1998. Fertigation Irrigation Training and Research Center (ITRC., California Polytechnich State University, San Luis Obispo, California, USA, 295.

Burt, C.M. and S.W. Styles, 2000. Riego por goteo y por microaspersíon para árboles, vides y cultivos anuales. Irrigation Training and Research Center (ITRC., California Polytechnich State University, San Luis Obispo, California, USA, 166.

Burt, C.M., 2004. Rapid field evaluation of drip and microspray distribution uniformity. Irrigation and Drainage System, 18 (4): 275-297. 
Candela, L., S. Fabregat, A. Josa, J. Suriol, N. Vigués, and J. Mas, 2007. Assessment of soil and groundwater impacts by treated urban wastewater reuse. A case study: Application in a golf course (Girona, Spain. Science of The Total Environment, 374: 26-35.

Cao, H., H. Sun, and H. Yang, 2003. A review: Soil enzyme activity and its indication for soil quality. Chinese Journal of Applied, and Environmental Biology, 9:105-109.

Cao, S.P., 2004. Vertical distribution of heavy metal pollutant in soil profile of Tianjin. Contributions to Geology, and Mineral Resources Research, 19:270-274.

Capra, A., and B. Scicolone, 1998. Water quality and distribution uniformity in drip/trickle irrigation systems. Journal of Agricultural Engineering Research, 70 (4): 335-365.

Capra, A., and B. Scicolone, 2004. Emitter and filter tests for wastewater reuse by drip irrigation. Agricultural Water Management, 68 (2):135-149.

Chakrabarti, C., 1995. Residual effects of long-term land application of domestic wastewater. Environment International, 21 (3): 333-339.

Chauhan H.S., 1995. Study approaches for trickle irrigation screen filters. Fifth International Microirrigation Congress, Orlando, Florida, USA. 597-602.

Chen, F., G.-G. Ying, L.-X. Kong, L. Wang, J.-L. Zhao, L.-J. Zhou, and L.-J. Zhang, 2011. Distribution and accumulation of endocrine-disrupting chemicals and pharmaceuticals in wastewater irrigated soils in Hebei, China. Environmental Pollution, 159: 1490-1498.

Chen, P.H., K.C. Leung, and J.T. Wang, 2000. Investigation of a ponding irrigation system to recycle agricultural wastewater. Environment International, 26: 63-68.

Chen, W., S. Lu, W. Jiao, M. Wang, and A.C. Chang, 2013a. Reclaimed water: A safe irrigation water source? Environmental Development, 8: 74-83.

Chen, Z.J., and J.B. Zhou, 2001. Application of Treated Wastewater on Agriculture in Israel. Agroenvironmental Protection, 20: 462- 464.

Cizmas, L., V. Sharma, C. Gray, and T. Mcdonald, 2015. Pharmaceuticals and personal care products in waters: occurrence, toxicity, and risk. Environmental Chemistry Letters, 13: 381-394

Clark G.A., D.Z. Hamam, J.F. Prochaska and M. Yitayew, 2007. General system design principles. In: Lamm F. R., Ayars J. E. and Nakayama F. S. (ed. Microirrigation for crop production: Design, Operation and Management. Developments in Agricultural Engineering 13, Elsevier, Amsterdam, The Netherlands,. 161-220.

Clark, G.A., and A.G. Smajstrla, 1999. Treating irrigation systems with chlorine. Circular No. 1039. Gainesville, Fla): University of Florida, Institute of Food and Agricultural Sciences

Coelho, R.D., and R.S. Resende, 2001. Biological clogging of Netafim's drippers and recovering process through chlorination impact treatment. ASAE Paper No. 012231. St. Joseph, Mich): ASAE.

Da Fonseca, A.F., U. Herpin, A.M. De Paula, R.L. Victoria, and A.J. Melfi, 2007. Agricultural use of treated sewage effluents: Agronomic and environmental implications and perspectives for Brazil. Scientia Agricola, 64: 194-209.

Dalai, R.C., 1977. Soil Organic Phosphorus. Advances in Agronomy, 29: 83-117.

Dalkmann, P., C. Siebe, W. Amelung, M. Schloter, and J. Siemens, 2014. Does long-term irrigation with untreated wastewater accelerate the dissipation of pharmaceuticals in soil? Environmental science, and technology, 48: 4963-4970.

Daniel, H., 1980. Application of Soil Physics, Academic Press, Inck.

Darby J.L. and D.F. Lawler 1989 Filtering ripening: measurement and predictions from a particle perspective. Proceeding of the American Water Work Association Annual Conference, American Water Work Association, Denver, Colorado, USA.

Darby J.L. and D.F. Lawler 1990. Ripening in depth filtration. Environmental Science and Technology, 24 (7): 1069-1079.

Dazhuang Y., B. Zhihui, M. Rowan, G. Likun, R. Shumei and Y. Peiling 2009. Biofilm Structure and its influence on clogging in drip irrigation emitters distributing reclaimed wastewater. Environmental Science, 21 (6): 834-841.

Deforest, J.L., D.R. Zak, K.S. Pregitzer, and A.J. Burton, 2004. Atmospheric nitrate deposition, microbial community composition, and enzyme activity in northern hardwood forests. Soil Science Society of America Journal, 68:132-138. 
Dehghanisanij, H., T. Yamamoto, B. Ould Ahmad, H. Fujiyama, and K. Miyamoto, 2005. The effect of chlorine on emitter clogging induced by algae and protozoa and the performance of drip irrigation. American Society of Agricultural Engineers, 48(2): 519-527.

Dheri, G.S., M.S. Brar, and S.S. Malhi, 2007. Heavy-Metal Concentration of Sewage Contaminated Water and Its Impact on Underground Water, Soil, and Crop Plants in Alluvial Soils of Northwestern India. Communications in Soil Science, and Plant Analysis, 38: 1353-1370.

Dryden, H.T., 2007. Drinking water: Improving sand filter performance. Filtration and Separation, 44 (5): $22-25$.

Du, B., J. Gong, and J.L. Li, 2010. Study on organic pollution of soil and water environment by sewage irrigation in Taiyuan City. Yangtze River, 41: 58-61.

English, S.D., 1985. Filtration and water treatment for microirrigation: Drip/trickle irrigation in action. In Proc. 3rd Int. Drip/Trickle Irrig. Congress, 50-68. St. Joseph, Mich): ASAE.

Environmental Protection Agency, 1992. Guidelines for Water Reuse. Washington DC.

Fang, Y.D., 2011. Research on the current situation, prevention and treatment of farmland wastewater irrigation in China. Journal of Agricultural Resources and Environment, 5:1-6.

Fatta-Kassinos, D., I.K. Kalavrouziotis, P.H. Koukoulakis, and M.I. Vasquez, 2011. The risks associated with wastewater reuse and xenobiotics in the agroecological environment. Science of the Total Environment 409: 3555-3563.

Feigin, A., I. Ravina, and J., Shalheret. 1991. Irrigation with Treated Sewage. Berlin, Germany: Springer-Verlag.

Food and Agriculture Organization, 1985. Water quality for irrigation, Irrigation and Drainage Paper. Rome.

Ford, H.W., 1978. Bacterial clogging in low-pressure irrigation systems. In Proc. Irrig. Association. Annual Technical Congress, 293-244. Cincinnati, Ohio: Silver Spring.

Francks, P., 1979. The development of new techniques in agriculture: The case of the mechanization of irrigation in the Saga Plain area of Japan. World Development 7:531-539.

Franzluebbers, A.J., S.F. Wright, and J.A. Stuedemann, 2000. Soil aggregation and Glomalin under pastures in the Southern Piedmont USA. Soil Science Society of America Journal, 64: 10181026.

Friedel, J., T. Langer, C. Siebe, and K. Stahr, 2000. Effects of long-term waste water irrigation on soil organic matter, soil microbial biomass and its activities in central Mexico. Biology and Fertility of Soils, 31: 414-421.

García, C., and T. Hernández, 1996. Influence of salinity on the biological and biochemical activity of a calciorthird soil. Plant and Soil, 178: 255-263.

Ge, H.L., L. Chen, J.L. Zhang, and W.S. Huang, 2009. Effect of Long-term Sewage Irrigation on Rhizosphere Soil Microbial Populations of Wheat. Water Saving Irrigation, 5: 14-15.

Gilbert, R.G., F.S. Nakayama, and D.A. Bucks, 1979. Trickle irrigation: Prevention of clogging. Trans. ASAE, 22(3): 514-519.

Gu, S., A. Jenkins, S.J. Gao, Y. Lu, H. Li, Y. Li, R.C. Ferrier, M. Bailey, Y. Wang, and Y. Zhang, 2017. Ensuring water resource security in China; the need for advances in evidence-based policy to support sustainable management. Environmental Science, and Policy, 75:65-69.

Gushiken E.C.,1995. Irrigate with reclaimed water through permanent subsurface drip irrigation system. Proceedings of the International Microirrigation congress, Orlando, Florida, USA, 269-274.

GWENZI, W., and MUNONDO, R. 2008. Long-term impacts of pasture irrigation with treated sewage effluent on shallow groundwater quality. Water Science and Technology, 58: 2443-2452.

Haman D.Z., A.G. Smajstrla and Zazueta F.S. 1994. Media filters for trickle irrigation in Florida. AE57, Agricultural and Biological Engineering Department, Florida cooperative Extension Service, Institute of Food and Agricultural Science, University of Florida, Gainesville, Florida, USA.

Hamilton A.J., F. Stagnitti, V.L. Versace, P. Li, K. Hermon, R.R. Premier and D. Lerodiaconou 2006. Balancing environmental impacts and benefits of wastewater reuse. WSEAS Transactions of Environmental Developmental, 2 (2): 117-129.

Hamilton A.J., X.F. Stagnitti, S.L. Kreidl, K.K. Benke and P. Maher 2007. Wastewater irrigation: The state of play. Vadose Zone Journal, 6 (4): 823-840.

Hanson, B., L. Schwankl, S.R. Grattan, and T. Pritchard, 1994. Drip irrigation for row crops. Water Management Series Publication 93-05. University of California Irrigation Program, Davis. 175. 
Haruta S., W. Chen, J. Gan, J. Simunek, A.C. Chang and L. Wu 2008. Leaching risk of N nitrodimethyleamine (NDMA. in soil receiving reclaimed wastewater. Ecotoxicology and Environmental safety, 69: 374-380.

Haruvy, N. 1998. Wastewater reuse-regional and economic consideration. Resources, conservation and Recycling, 23 (1-2): 57-66.

Hills D.J. and M.J. Brenes 2001. Microirrigation of wastewater effluent using drip tape. Applied Engineering in Agriculture, 17 (3): 303-308.

Hills D.J., F.M. Anwar and P.M. Waller 1989. Effect of chemical clogging on drip-tape irrigation uniformity. Transactions of the ASAE, 32 (4): 1202-1206.

Hills, D.J., and M. Tajrishy. 1995. Treatments requirements of secondary effluent for microirrigation. In Proc. 5th Int. Microirrigation Congress, 884-890. F. R. Lamm, ed. St. Joseph, Mich): ASAE

Hu, H.R., H.C. Ma, and Y.X. Wang, 2010. Influence of Land Use Types to Nutrients, Organic Carbon and Organic Nitrogen of Soil. Soil, and Water Conservation in China 11: 40-43.

Hu, H.R., H.L. Wang, B. Katie, and K. Mark, 2012. Effect of long-term effluent irrigation on content and movement of phosphorus in soil of forest land. Acta Pedologica Sinica, 49:560-566.

Hu, H.Y., 2010. Effect of sewage irrigation water on soil quality in farmland. Northwest A, and F University, Yangling.

Hu, K.L., F.R. Zhang, L. Hong, F. Huang, and B.G. Li, 2006. Spatial Patterns of Soil Heavy Metals in Urban-Rural Transition Zone of Beijing. Pedosphere 16: 690-698.

Huang, C.Y., 2000. Soil Science. China Agriculture Press, Beijing.

Hussain, I., L. Raschid, M.A. Hanjra, F. Marikar, and W. Van Der Hoek, 2002. Wastewater Use in Agriculture: Review of Impacts and Methodological Issues in Valuing Impacts: with an Extended List of Bibliographical References, Iwmi.

Jackson R.B., S.R. Carpenter, C.N. Dahm, D.M. McKnight, R.J. Naiman, S.L. Postel and S.W. Running 2001. Water in changing world. Ecological Applications, 11 (4): 1027-1045.

Jia, F., and G.S. Fan, 2007. Study on the relationship between soil texture and field water holding rate. Soil and Water Conservation Science and Technology in Shanxi, 3:17-19.

Jin, L.S., and W. Young, 2001. Water Use in Agriculture in China: Importance, Challenges, and Implications for Policy. Water Policy 3: 215-228.

Journal of Irrigation and Drainage Engineering, 112 (4): 293-304

Jueschke, E., B. Marschner, J. Tarchitzky, and Y. Chen, 2008. Effects of treated wastewater irrigation on the dissolved and soil organic carbon in Israeli soils. Water Science, and Technology A Journal of the International Association on Water Pollution Research, 57: 727-733.

Kaddous F.A.G. and K.J. Stubbs 1983. Growth of vegetables with reclaimed water. Ministry of Water Resources and Water Supply, Reclaimed Water Committee, Melbourne, Australia.

Karmeli, D., 1977. Classification and flow regime analysis of drippers. J. Agric. Eng. Res. 22(2): $165-173$

Karr, J.R., 1991. Biological Integrity: A Long-Neglected Aspect of Water Resource Management. Ecological Applications, 1: 66-84.

Keesstra, S.D., V. Geissen, K. Mosse, S. Piiranen, E. Scudiero, M. Leistra, and L. van Schaik, 2012. Soil as a filter for groundwater quality. Current Opinion in Environmental Sustainability, 4: 507516.

Keller, J., and R.D. Bliesner. 1990. Sprinkle and Trickle Irrigation. New York, N.Y): Van Nostrand Reinhold.

Khan, S., Q. Cao, Y.M. Zheng, Y.Z. Huang, and Y.G. Zhu, 2008. Health risks of heavy metals in contaminated soils and food crops irrigated with wastewaRter in Beijing, China. Environmental Pollution, 152: 686-692.

Killham, K., 1994. Soil Ecology. Cambrige Unisity Press, Cambrige.

Kiziloglu F. M., M. Turan, U. Sahin, Y. Kuslu and A. Dursun 2008. Effects of untreated and treated wastewater irrigation on some chemical properties of cauliflower Brassica olerecea L. var. botrytis. and red cabbage (Brassica olerecea L. var. rubra. grown on calcareous soil in Turkey. Agricultural Water Management, 95 (6): 716-724.

Knobeloch, L., B. Salna, A. Hogan, J. Postle, and H. Anderson, 2000. Blue babies and nitratecontaminated well water. Environmental Health Perspectives, 108: 675. 
Lamm F.R., 2002. Advantages and disadvantages of subsurface drip irrigation. International Meeting and Advances in Drip/Micro Irrigatio, Puerto de la Cruz, Spain.

Lamm, F.R., G.A. Clark, M. Yitayew, R.A. Schoneman, R.M. Mead, and A.D. Schneider, 1997. Installation issues for SDI systems. ASAE Paper 972074 from ASAE, St. Joseph, MI. 6.

Lan, M.J., M.S. Li, G.J. Zhao, and L. Rui, 2000. Effects of Eutrophic Sewage Irrigation on Soil holding Capacity. Journal of Shihezi University, 28: 497-500.

Lazarova, V. 2005. Wastewater treatment for water recycling. In: Lazarova V. and Bahri A. Water reuse for irrigation- Agriculture, Landscape and Turf grass. CRC Press, Washington D. C., USA.

Lazarova, V. and T. Asano 2005. Challenges of sustainable irrigation with recycled water. In: Lazarova and Bahri A. Water reuse of irrigation-Agriculture, Landscape and Turf grass. CRC Press, Washington D. C., USA.

Leverenz, H.L., G. Tchobanoglous and J.I. Darby 2009. Clogging in intermittently dosed sand filters used for wastewater treatment. Water Research, 43 (3): 695-705.

Li G.B., K.Y. Li, T.W. Xu, Y.Z. Liu, H. Jin, P.L. Yang, D.Z. Yang, S.M. Ren and Z.F. Tian 2011. Effects of average velocity on the growth and surface topography of biofilms attached to the reclaimed wastewater drip irrigation system laterals. Irrigation Science, Sring-Verlag, Heidelberg, Germany, 1-11.

Li Y.K., Z. Liu., G.B. Li, T.W. Xu, H.S. Liu, S.M. Ren, D.Z. Yan and P.L. Yang 2010. Surface topographic characteristics of suspended particles in reclaimed wastewater and effect on clogging in labyrinth drip irrigation emitters. Irrigation Science, Springer-verlag, Heidelberg, Germany, $1-14$.

Li, B., C. Yang, and P. Lin, 2000. Ecology. Higher Education Press, Beijing.

Li, F., G. Huang, Y. Ding, and C. Peng, 2006. Effects of soil alkalinity, gypsum application, and filtration disposal on hydraulic conductivity under irrigation with domestic effluent water. Transactions of the Chinese Society of Agricultural Engineering, 22: 48-52.

Li, F., M. Benhur, and R. Keren, 2003. Effect of marginal water irrigation on soil salinity, sodicity and crop yield. Transactions of the Chinese Society of Agricultural Engineering, 19:63-66.

Li, H., G. Chen, T. Yang, and C.G. Zhang, 2005. Impacts of petroleum-containing wastewater irrigation on microbial population and enzyme activities in paddy soil of Shenfu irrigation area. Chinese Journal of Applied Ecology, 16: 1355-1359.

Li, L.Q., 2001. Study on properties of physies and chemistry of cinnamon soil with wastewater irrigation. Journal of Shanxi Agricultural University 21: 73-75.

Li, S.Z., and J.F. Luo, 1995. Sewage irrigation and environmental quality control in China. China Meteorological Press, Bejing.

Li, Y.S., C.L. Feng, X.F. Wu, and R. Shi, 2015. A review on the functions of microorganisms in the phytoremediation of heavy metal-contaminated soils. Acta Ecologica Sinica, 35:6881-6890.

Liu H. and G. Huang 2009. Laboratory experiment on drip emitter clogging with fresh water and treated sewage effluent. Agricultural Water Management, 96 (5): 745-756.

Liu, L., and G.H. Lu, 2002. Nitrogen wastewater irrigation study and its contamination risk analysis. Advances in Water Science 13: 313-320.

Liu, R.T., and J.Z. Xu, 2002. Sewage water irrigation problems and solutions in China, China Water Resources, 10: 123-125.

Liu, S.Q., 1996. Relationship between soil $\mathrm{Pb}$ and $\mathrm{Cd}$ pollution and enzyme activities in wastewater irrigated area of baoding city. Acta Pedologica Sinica 33: 175-182.

Liu, W. H., J.Z. Zhao, Z.Y. Ouyang, L. Söderlund, and G.H. Liu, 2005. Impacts of sewage irrigation on heavy metal distribution and contamination in Beijing, China. Environment International 31: 805-812.

Loska, K., D. Wiechuła, and I. Korus, 2004. Metal contamination of farming soils affected by industry. Environment International 30: 159-165.

Lottermoser, B.G., 2012. Effect of long-term irrigation with sewage effluent on the metal content of soils, Berlin, Germany. Environmental Geochemistry, and Health 34: 67-76.

Ma, Q., and G.X. Zhao, 2010. Effects of different land use types on soil nutrients in intensive agricultural region. Journal of Natural Resources 25: 1834-1844.

Maestre-Valero J. F. and V. Martínez-Álvarez 2010. Effect of drip irrigation systems on the recovery of dissolved oxygen from hypoxic water. Agricultural Water Management, 97 (11): 1806-1812. 
Magesan G.N., J.C. Williamson, G.W. Yetes and A.R.H. Lloyd-Jones 2000. Wastewater C:N ratio effects on soil hydraulic conductivity and potential mechanisms for recovery. Bioresource Technology, 71 (1): 21-27.

Mapanda, F., and E.N. Mangwayana, 2005. The Effects of long-term irrigation using water on heavy metal contents of soils under vegetables. Agriculture Ecosystems, and Environment, 107: 151165.

Marecos Do Monte, M.H.F., 1998. Agricultural irrigation with treated wastewater in Portugal. In: Asano, T. Wastewater reclamation and reuse. CRC Press, Boca, Raton, Florida, USA.

Marschner, P., Z. Solaiman, and Z. Rengel, 2007. Brassica genotypes differ in growth, phosphorus uptake and rhizosphere properties under P-limiting conditions. Soil Biology, and Biochemistry 39: 87-98.

Masto, R.E., P.K. Chhonkar, D. Singh, and A.K. Patra, 2009. Changes in soil quality indicators under long-term sewage irrigation in a sub-tropical environment. Environmental Geology 56: 1237 1243.

McDonald, D.R., L.S. Lau, I.P. Wu, H.K. Gee, and S.C.H. Young 1984. Improved emitter and network system design for reuse of wastewater in drip irrigation. Technical Report No. 163, Water Resources Center, University of Hawaii, Honolulu, Hawaii, USA.

Medina, J.A. 1988. Riego por goteo. Tercera Edición Mundi-Prensa, Madrid, Spain.

Meli S., M. Porto, A. Belligno, S.A. Bufo, A. Mazzatura and A. Scopa 2002. Influence of irrigation with lagooned urban wastewater on chemical and microbiological soil parameters in a citrus orchard Mediterranean conditions. Science of the Total Environment, 285 (1-3): 69-77.

Meng, W.Q., Z.W. Wang, B.B. Hu, Z.L. Wang, H.Y. Li, and R.C. Goodman, 2016. Heavy metals in soil and plants after long-term sewage irrigation at Tianjin China: A case study assessment. Agricultural Water Management 171: 153-161.

Molles, M., 2008. Ecology. Concepts and Application. McGraw- Hill Education, London.

Morishita, T., 1988. Environmental hazards of sewage and industrial effluents on irrigated farmlands in Japan. Elsevier Ltd, London.

Mullins, G.L., D.W. Reeves, C.H. Burmester, and H.H. Bryant, 1994. In-row subsoiling and potassium placement effects on root growth and potassium content of cotton. Agronomy Journal 86: 136139.

Muñoz, I., M.J. Gómez-Ramos, A. Agüera, A.R. Fernández-Alba, J.F. García-Reyes, and A. MolinaDíaz, 2009. Chemical evaluation of contaminants in wastewater effluents and the environmental risk of reusing effluents in agriculture. TrAC Trends in Analytical Chemistry, 28: 676-694.

Muyen, Z., G.A. Moore, and R. J. Wrigley, 2011. Soil salinity and sodicity effects of wastewater irrigation in South East Australia. Agricultural Water Management, 99: 33-41.

Naghavi B. and R.F. Malone 1986. Algae removal by fine sand/sit filtration. Water Resources, 20 (3): 377-383.

Nakayama F. S., R.G. Gilbert and D.A. Bucks 1978. Water treatment in trickle irrigation systems. Journal of the Irrigation and Drainage Division, 1041 (IR1): 23-34.

Nakayama F.S., B.J. Bowman, and D.J. Pi s 2007. Maintenance In: Lamm F. R., Ayers J. E and Nakayama F. S. (ed. Microirrigation for crop production: Design, Operation and Management. Developments in Agricultural Engineering 13. Elsevier, Amsterdam, The Netherlands, 389-430.

Nakayama, F.S., and D.A. Bucks. 1986. Trickle Irrigation for Crop Production: Design, Operation, and Management, 3.2: 164-187. Amsterdam, The Netherlands: Elsevier Science

Neufeld J., J. Davison and T. Stevenson 1997. Subsurface Drip Irrigation. University of Nevada Cooperative Extension Fact Sheet 97-13. Reno, Nevada, USA.

Onesios, K.M., T.Y. Jim, and E.J. Bouwer, 2009. Biodegradation and removal of pharmaceuticals and personal care products in treatment systems: a review. Biodegradation, 20: 441-466

Oron G., G. Shelef and B. Turzynski 1979. Trickle irrigation using treated wastewaters. Journal of Irrigation and Drainage Division.105 (IR2): 175-186.

Oron G., R. Armon, Y. Mandelbaum Manor, C. Campos, L. Gillerman, Salgot M., Yerba C., Kelin I. and Enriquez C. 2001. Secondary wastewater disposal with minimal risks. Water Science and Technology, 43 (10): 103-108. 
Oron G., Y. DeMalash, Z. Ho man, and Y. Manor 1992a. Effect of effluent quality and application method on agricultural productivity and environmental control. Water Science and Technology, 26 (7-8): 1593-1601.

Oron G., DeMalash Y., Ho man Z., Manor Y. 1992b. Effluent reuse by trickle irrigation. Water Science and Technology, 24 (9): 103-108.

Oron, G., C. Campos, L. Gillerman, and M. Salgot, 1999. Wastewater treatment, renovation and reuse for agricultural irrigation in small communities. Agricultural Water Management 38: 223-234.

Oron, M.G., M. Goemans, Y. Manor, and J. Feyen, 1995. Poliovirus distribution in the soil plant system under reuse of secondary wastewater. Water Research: 29: 1069-1078.

Owusu, V., J.-E.A. Bakang, R.C. Abaidoo, and M.L. Kinane, 2012. Perception on untreated wastewater irrigation for vegetable production in Ghana. Environment Development and Sustainability, 14: 135-150.

Pereira, L.S., S.T. Owens and A. Zairi 2002. Irrigation management under water scarcity. Agricultural Water Management, 57 (3): 175-206.

Piao, S., P. Ciais, Y. Huang, Z. Shen, S. Peng, J. Li, L. Zhou, H. Liu, Y. Ma, and Y. Ding, 2010. The impacts of climate change on water resources and agriculture in China. Nature, 467: 43-47.

Pitts, D.J., D.Z. Haman and A.G. Smajstrla 1990. Causes and prevention of emitter plugging in microirrigation system. Bulletin 258, Florida Cooperative Extension Service, Institute of Food and Agriculture Science, University of Florida, Gainesville, Florida, USA.

Postel, S., 1992. The last oasis: Facing water scarcity. Worldwatch Institute, Washington, D.C., USA.

Prosser, R., and P. Sibley, 2015. Human health risk assessment of pharmaceuticals and personal care products in plant tissue due to biosolids and manure amendments, and wastewater irrigation. Environment international, 75: 223- 233

Purchas, D.B. and K. Sutherland 2002. Handbook of filter media. Second edition, Elsevier, Amsterdam, The Netherlands.

Qadir, M., B.R. Sharma, A. Bruggeman, R. Choukr-Allah, and F. Karajeh, 2007. Non conventional water resources and opportunities for water augmentation to achieve food security in water scarce countries. Agricultural Water Management, 87: 2-22.

Qadir, M., D. Wichelns, L. Raschidsally, P.G. Mccornick, P. Drechsel, A. Bahri, P.S. Minhas, D. Molden, and C. De Fraiture, 2010. The challenges of wastewater irrigation in developing countries. Agricultural Water Management: 97: 561-568.

Qin, Q., X. Chen, and J. Zhuang, 2015. The Fate and Impact of Pharmaceuticals and Personal Care Products in Agricultural Soils Irrigated With Reclaimed Water. Critical Reviews in Environmental Science and Technology, 45: 1379- 1408

Qin, Y.D., 2003. Soil Physics. Higher Education Press, Beijing.

Rajkumar, M., N. Ae, M. Prasad, and H. Freitas, 2010. Potential of siderophore-producing bacteria for improving heavy metal phytoextraction. Trends in Biotechnology, 28: 142149.

Ramirez, K. S., J.M. Craine, and N. Fierer, 2012. Consistent effects of nitrogen amendments on soil microbial communities and processes across biomes. Global Change Biology, 18: 1918-1927.

Ramirez-Fuentes, E., C. Lucho-Constantino, E. Escamilla-Silva and L. Dendooven 2002. Characteristics and carbon and nitrogen dynamics in soil irrigated with wastewater for different lengths of time. Bioresource Technology, 85 (2): 197-187.

Rattan, R.K., S.P. Datta, P.K. Chhonkar, K. Suribabu, and A.K. Singh, 2005. Long-term impact of irrigation with sewage effluents on heavy metal content in soils, crops and groundwater--a case study. Agriculture Ecosystems, and Environment, 109: 310-322.

Rav-Acha, C.H., M. Kummel, I. Salamon, and A. Adin. 1995. The effect of chemical oxidants on effluent constituent for drip irrigation. Water Res., 25(1): 119-129.

Ravina A, E. Paz, Z. Sofer, A. Marcu, A. Shisha, G. Sagi, Z. Yechialy and Y. Lev 1997. Control of emitter clogging in drip irrigation with stored treated municipal sewage effluent. Agricultural Water Management, 33 (2-3): 127-137.

Ravina, I., E. Paz, A. Sofer, A. Marcu, A. Schischa, and G. Sagi. 1992. Control of emitter clogging in drip irrigation with reclaimed wastewater. Irrig. Sci., 13(3): 129-139.

Recommendations for revising WHO guidelines. Bulletin of the World Health Organization, 78(9.,1104-1116. 
Redding, M.R., A. Biggs, T. Gardner, and D. Duperouzel, 2002. An overview of land application of pig effluent-P using soil P chemistry and mass balance calculations. Soil Research, 40: 81-91.

Reminders F.B., 2006. Micro-irrigation: world overview on Technology and utilization. Keynote address at the opening of the Seventh International Micro-Irrigation Congress, Kuala Lumpur, Malaysia.

Rietz, D.N., and R.J. Haynes, 2003. Effects of irrigation-induced salinity and sodicity on soil microbial activity. Soil Biology and Biochemistry, 35: 845-854.

Rodriguez, C., 1990. Evaluación de instalaciones de microirrigación. IV Curso de Tecnología del riego. ETSIA, Universidad Politécnica de Catalunya, Lleida, Spain.

Rusan, M.J.M., S. Hinnawi, and L. Rousan, 2007. Long term effect of wastewater irrigation of forage crops on soil and plant quality parameters. Desalination 215: 143-152.

Sabol, G.V., H. Bouwer, and P.J. Wierenga, 1987. Irrigation Effects in Arizona and New Mexico. Journal of Irrigation, and Drainage Engineering, 113: 30-48.

Sagi, G., E. Paz, I. Ravina, A. Schischa, A. Marcu, and Z. Yechieli, 1995. Clogging of drip irrigation systems by colonial protozoa and sulfur bacteria. In Proc. 5th Int. Microirrigation Congress, 250-259. F. R. Lamm, ed. St. Joseph, Mich): ASAE.

Sala L. and M. Serra 2004. Towards sustainability in water recycling. Water Science and Technology.50 (2): 1-4.

Sala L. and R. Mujeriego 2001. Cultural eutrophication control through water reuse. Water Science and Technology, 43 (10): 109-116.

Sawa A.P. and K. Frenken 2002. Irrigation manual: Planning, development, monitoring and evaluation of agriculture with farmer participation. Food and Agriculture Organization of the United Nations (FAO., Sub-Regional Office for East and Southern Africa (SAFR., Harare, Zimbabwe.

Shao, M.A., Q.J. Wang, and M.B. Huang, 2006. Soil physics. Higher Education Press, Beijing.

Sheikh B., R. Cort, R.C. Cooper and R.S. Jaques 1998. Tertiary treated reclaimed water for irrigation of raw eaten vegetables. In: Asano, T.(ed. Wastewater reclamation and reuse, CRC Press, Boca, Florida, USA.

Shi, R.G., D.R. Wang, Y.J. Zhao, F.Z. Liu, H.Y. Gao, Y.M. Cai, and Y. Shen, 2006. Water quality control indexes of reclaimed municipal wastewater for farmland irrigation. China Water, and Wastewater, 22: 100-104.

Shi, R.G., Q.X. Zhou, F.Z. Liu, Y.J. Zhao, X.Q. Zheng, Y.M. Cai, and D.R. Wang, 2008. Water quality standard and irrigation regulation of reclaimed water from municipal wastewater for farmland irrigation. Journal of Agro-Environment Science, 27: 839-843.

Shi, Y., Q. XB, and Q. Gao, 2014. Advance in Sewage Irrigation Safety Research and Proposal Countermeasure in China. Water Saving Irrigation, 3: 37-44.

Siebe, C., and W.R. Fischer, 1996. Effect of long-term irrigation with untreated sewage effluents on soil properties and heavy metal adsorption of leptosols and vertisols in Central Mexico. Journal of Plant Nutrition, and Soil Science, 159: 357-364.

Singh, P.K., P.B. Deshbhratar, and D.S. Ramteke, 2012. Effects of sewage wastewater irrigation on soil properties, crop yield and environment. Agricultural Water Management, 103:100-104.

Smajstrla A.G. and B.J. Boman 1998. Flushing procedures for microirrigation systems. Bullen 333. Florida Cooperative Extension Service, Institute of Food and Agricultural Science, University of Florida, USA.

Stenberg, B., 1999. Monitoring soil quality of arable land: microbiological indicators. Acta Agriculturae Scandinavica 49: 1-24.

Sun, L.N., Y.H. Zhang, T.H. Sun, Z.Q. Gong, X. Lin, and H.B. Li, 2006. Temporal-spatial distribution and variability of cadmium contamination in soils in Shenyang Zhangshi irrigation area, China. Journal of Environmental Sciences, 18: 1241-1246.

Tajrishy, M.A., D.J. Hills and G. Tchobanoglobus 1994. Pretreatment of secondary effluent for drip irrigation. Journal of Irrigation and Drainage Engineering, 120 (4): 716-731.

Tang, C., J. Chen, S. Shindo, Y. Sakura, W. Zhang, and Y. Shen, 2004. Assessment of groundwater contamination by nitrates associated with wastewater irrigation: A case study in Shijiazhuang region, China. Hydrological Processes, 18: 2303-2312.

Thomas, A., 2008. Agricultural irrigation demand under present and future climate scenarios in China. Global, and Planetary Change, 60: 306-326. 
Tian, J.Y., H.K. Zhang, J.M. Bao, and F.H. Wang, 1993. Organic Compound Pollution in Xiaoqing River and its Influence on Ecosystem of Sewage-Irrigatcd Area. Chinese Journal of Ecology, 12: $14-22$.

TOZE, S. 2006a. Reuse of effluent water-benefits and risks. Agricultural Water Management, 80, 147-159.

Toze, S., 2006b. Water reuse and health risks — real vs. perceived. Desalination, 187: 41-51.

Trooien T. P. and Hills D. J. 2007. Application of biological effluent. In: Lamm F. R., Ayars J. E. and Nakayama F. S. (ed. Microirrigation for crop production: Design, Operation and Management. Developments in Agricultural Engineering 13, Elsevier, Amsterdam, The Netherlands,. 329-356.

Trooien T.P., F.R. Lamm, L.R. Stone, M. Alam, D.H. Rogers, G.A. Clark and A.J. Schlegel 2000. Subsurface drip irrigation using livestock wastewater: driplines flow rates. Applied Engineering in Agriculture, 16 (5): 505-508.

USEPA. 1998. Handbook: Optimizing water treatment plant performance using the composit correction program. United States Environmental Protection Agency, Cincinnati, USA.

Vermeiren, L. and G.A. Jobling, 1986. Riego localizado. Estudios FAO. Riego y Drenaje. 36, Food and Agricultural Organization, Rome, Italy.

Wakeman, R., 2007. Filter media: Testing for liquid filtration, 7 (2): 138-147.

Wallach, R., O. Ben-Arie, and E.R. Graber, 2005. Soil water repellency induced by long-term irrigation with treated sewage effluent. Journal of Environmental Quality, 34: 1910-1920.

Wan, L., M.R. Zhang, S. Lu, and K. Hu, 2015. Study progress on effect of polluted water irrigation on soil and problem analysis. Ecology and Environmental Sciences, 24: 906-910.

Wang, G.L., and W.J. Lin, 2003. Contamination of soil from sewage irrigation and its remediation. Journal of Agro-environmental Science, 22: 163-166.

Wang, G.L., C.Z. Liu, Z.Y. Lu, and A.P. Wang, 2006. Influences of sewage irrigation on the field soil quality in Baiyin City. Journal of Gansu Agricultural University, 41: 79-82.

Wang, Y., L.X. Sheng, K. Li, and H.Y. Sun, 2008. Analysis of present situation of water resources and countermeasures for sustainable development in China. Journal of Water Resources, and Water Engineering, 19: 10-14.

Wang, Y.Q., S.Y. Li, and X.D. Cai, 2010. Advance of Research on Sewage Irrigation in Farmland in China. Tianjin Agricultural Sciences, 16: 77-80.

Weber, S., S. Khan, and J. Hollender, 2006. Human risk assessment of organic contaminants in reclaimed wastewater used for irrigation. Desalination, 187: 53-64.

Wescott, D.W., 1997. Quality control of wastewater for irrigated crop production. FAO, Rome.

WHO, 2006. Guidelines for the microbiological quality of treated wastewater used in agriculture:

Wiel-Shafran, A., Z. Ronen, N. Weisbrod, E. Adar, and A. Gross, 2006. Potential changes in soil properties following irrigation with surfactant-rich greywater. Ecological Engineering, 26: 348354.

World Resource Institute, 2000. Projected annual renewable water supply per person by river, basin, 2025. Resource Institute, Washington, D.C., USA.

Wright, P.J.,1993. Effects of nitrogen fertilizer, plant maturity, at lifting and water during field curing on the incidence of soft rot of onions in store. New Zealand Journal of Crop Horticulture Science, 21 (4): 377-381.

Wu, I.P., J. Barragán and V. Bralts 2007. Field performance and evaluation In: Lamm F. R., Ayars J. E. and Nakayama F. S.(ed. Microirrigation for crop production: Design, Operation and Management. Developments in Agricultural Engineering 13, Elsevier, Amsterdam, The Netherlands,. 357-387.

Wu, X., J.L. Conkle, F. Ernst, and J. Gan, 2014. Treated wastewater irrigation: uptake of pharmaceutical and personal care products by common vegetables under field conditions. Environmental science, and technology, 48: 11286- 11293.

Wu, X., L.K. Dodgen, J.L. Conkle, and J. Gan, 2015. Plant uptake of pharmaceutical and personal care products from recycled water and biosolids: a review. Science of The Total Environment, 536: 655-666.

Xia, J.B., W.J. Xie, J.K. Sun, J.T. Liu, Q. Liu, and Z.H. Lu, 2011. Effects of paper-making wastewater irrigation on reed growth and its soil improvement. Journal of Soil, and Water Conservation 25: 110-109. 
Xia, L.J., and H.K. Wang, 2001. Soil pollution and countermeasures. Huazhong University of Science Press, Wuhan.

$\mathrm{Xu}, \mathrm{G} ., 2$ 2007. Effect of sewage irrigation with molasses alcohol waterwater on soil quality. Guangxi University, Nanning.

Xue, Z.J., 2012. Assessment of soil quality and pollution risk in main sewage-irrigated area of Hebei province. Agricultural University of Hebei Province, Baoding.

Yan D., P. Yang, M. Rowan, S. Ren and D. Pitts 2010. Biofilm accumulation and structure in the flow path of drip emitters using reclaimed wastewater. Transaction of the ASABE, 53 (3): 751-758

Zeng, D.F., and W.B. Zhu, 2004. Discussion on problems of sewage irrigation and countermeasures in China. Agricultural Research in the Arid Areas, 22: 221-224.

Zeng, X.B., L.F. Li, and X.R. Mei, 2007. Heavy metal content in soils of vegetable-growing lands in China and source analysis. Scientia Agricultura Sinica, 40: 2507-2517.

Zhang, D.G., Y.L. Yi, and X.L. Zheng, 2003. Effect of Petroleum Groups on Soil and Rice in the Shen$\mathrm{Fu}$ Irrigation Region. Chinese Journal of Soil Science 34: 333-336.

Zhang, J., H.W. Zhang, Q. Zhang, and C.G. Zhang, 2008. Impact of long-time irrigation of petroleum wastewater on glebe microbial biomass and soil enzyme activities in Northeast China. Chinese Journal of Eco-Agriculture, 16: 67-70.

Zhang, J., H.W. Zhang, Z.C. Su, X.Y. Li, and C.G. Zhang, 2007. The Effect of Long-term Organic Wastewater Irrigation on the soil nitrogen-fixing bacteria population. Journal of AgroEnvironment Science, 26: 662-666.

Zhang, J.Y., and G.Q. Wang, 2007. The impacts of climate change on hydrology and water resources. Science Press, Beijing.

Zhang, L.H., 2014. China's early exploration in sewage irrigation and pollution prevention (1949-1972. Researches Economic History, 2: 153-165.

Zhang, L.J., X.Q. Huang, F. Wu, and H.Q. Wu, 2005. Study of Agricultural Tridimension Pollution on Irrigation Farmland and Its Control Tactics. Journal of Irrigation, and Drainage, 24: 1-5.

Zhang, M.K., L.J. Liu, and C. Huang, 2011. Effects of Long-term Irrigation of Livestock Farm Wastewater on Soil Quality and Vegetable Quality in Vegetable Soils. Journal of Soil, and Water Conservation, 25: 87-91.

Zhang, W.L., Z.X. Tian, N. Zhang, and X.Q. Li, 1996. Nitrate pollution of groundwater in northern China. Agriculture Ecosystems, and Environment 59: 223-231.

Zhang, Y.L., J.L. Dai, and R.Q. Wangab, 2008. Effects of long-term sewage irrigation on agricultural soil microbial structural and functional characterizations in Shandong, China. European Journal of Soil Biology 44: 84-91. 